\title{
Microscopic emission and reflectance thermal infrared spectroscopy: instrumentation for quantitative in situ mineralogy of complex planetary surfaces
}

\author{
C. S. Edwards ${ }^{1,2, *}$ and P. R. Christensen ${ }^{2}$ \\ ${ }^{1}$ California Institute of Technology, Division of Geological and Planetary Sciences, \\ 1200 E. California Blvd., MC 150-21, Pasadena, California 91125, USA \\ ${ }^{2}$ Arizona State University, School of Earth and Space Exploration, Mars Space Flight Facility, \\ P.O. BOX 876305, Tempe, Arizona 85287-6305, USA \\ *Corresponding author: cedwards@caltech.edu \\ Received 9 November 2012; accepted 14 February 2013; \\ posted 21 February 2013 (Doc. ID 179165); published 3 April 2013
}

\begin{abstract}
The diversity of investigations of planetary surfaces, especially Mars, using in situ instrumentation over the last decade is unprecedented in the exploration history of our solar system. The style of instrumentation that landed spacecraft can support is dependent on several parameters, including mass, power consumption, instrument complexity, cost, and desired measurement type (e.g., chemistry, mineralogy, petrology, morphology, etc.), all of which must be evaluated when deciding an appropriate spacecraft payload. We present a laboratory technique for a microscopic emission and reflectance spectrometer for the analysis of martian analog materials as a strong candidate for the next generation of in situ instruments designed to definitively assess sample mineralogy and petrology while preserving geologic context. We discuss the instrument capabilities, signal and noise, and overall system performance. We evaluate the ability of this instrument to quantitatively determine sample mineralogy, including bulk mineral abundances. This capability is greatly enhanced. Whereas the number of mineral components observed from existing emission spectrometers is high (often $>5$ to 10 depending on the number of accessory and alteration phases present), the number of mineral components at any microscopic measurement spot is low (typically $<2$ to 3 ). Since this style of instrument is based on a long heritage of thermal infrared emission spectrometers sent to orbit (the thermal emission spectrometer), sent to planetary surfaces [the minithermal emission spectrometers (mini-TES)], and evaluated in laboratory environments (e.g., the Arizona State University emission spectrometer laboratory), direct comparisons to existing data are uniquely possible with this style of instrument. The ability to obtain bulk mineralogy and atmospheric data, much in the same manner as the mini-TESs, is of significant additional value and maintains the long history of atmospheric monitoring for Mars. Miniaturization of this instrument has also been demonstrated, as the same microscope objective has been mounted to a flight-spare mini-TES. Further miniaturization of this instrument is straightforward with modern electronics, and the development of this instrument as an arm-mounted device is the end goal. (C) 2013 Optical Society of America
\end{abstract}

OCIS codes: $\quad 300.6340,300.6190$.

\section{Introduction}

Over the last several decades, the range and volume of data returned from planetary exploration missions have increased exponentially. The orbital missions

$1559-128 \mathrm{X} / 13 / 112200-18 \$ 15.00 / 0$

(C) 2013 Optical Society of America responsible for the bulk of this data have traveled throughout our solar system to nearly every planetary-scale body, including but not limited to the MESSENGER, Venus Express, Lunar Reconnaissance Orbiter, Hayabusa, Chandrayaan-1, Mars Global Surveyor, 2001 Mars Odyssey, Mars Express, Mars Reconnaissance Orbiter, Galileo, and CassiniHuygens missions. These orbiters have carried a 
wide range of specialized instruments, ranging from high-resolution imaging visible cameras, radar, laser altimeters, magnetometers, and a wide range of spectrometers, including gamma ray and neutron spectrometers, thermal emission spectrometers (TES), and visible/near-infrared reflectance spectrometers. While fundamental observations have been made from these orbital instruments, the next generation of instruments to be deployed throughout the solar system will build on the remotely sensed characterization of planetary surfaces to perform in situ characterization of planetary material.

\section{A. In Situ and Remote Sensing Observations of Mars from Lander Data}

The trajectory toward in situ instrumentation is largely under way in the case of the martian surface. A concerted effort has been made over the last decade to characterize the surface in situ and in unprecedented detail. Most notably after the Viking missions, the recent reinvigoration of the Mars exploration program began with Mars Pathfinder as a lander technology demonstration, continued with the Mars Exploration Rovers (MERs) and the Phoenix lander, and to date has culminated with the Mars Science Laboratory (MSL). These landed spacecraft missions have characterized martian surface in detail using a variety of in situ and landed remote sensing techniques. For example onboard, the MERs, a broad suite of instruments including the alphaparticle x-ray spectrometer (APXS, [1]), Mössbauer (MB, [2]), Microscopic Imager (MI, [3]), the minithermal emission spectrometer (mini-TES, [4]), and the Panoramic Camera (PanCam, [5]) have characterized in detail both Meridiani Planum and a section of the floor of the Gusev Crater. The combination of in situ (e.g., MI, APXS, MB) and remote sensing (e.g., PanCam, mini-TES) instruments has proved to be especially successful in both identifying potential targets at a distance and characterizing those targets in detail [6-15]. Many of these observations have fundamentally changed our understanding of Mars and Mars surface processes.

Following the relatively modest MER instrument suite, the MSL instruments suite includes a host of largely in situ instruments designed to assess the habitability of past and present Mars. These instruments include the Mast Camera [16], a laser induced breakdown spectrometer for remote elemental composition (ChemCam, [17,18]), a microscopic imager (MAHLI, [19]), an APXS [16], and chemistry and mineralogy by powder x-ray diffraction and x-ray fluorescence (CheMin, [20]), as well as a quadrupole mass spectrometer, a gas chromatograph, and a tunable laser spectrometer (SAM, [21]). This suite of instruments onboard MSL will characterize the martian surface in unprecedented detail, rivaling what can be done in the laboratory on Earth. However, the time to make many of the measurements is exceedingly long, including sample preparation of several hours and integration times for the ChemMin instrument of many hours for a single measurement. Additionally, the power requirement for highly complex instruments and long measurement times is prohibitively costly and requires the use of a radioisotope thermoelectric generator, which dramatically increases the cost of planetary missions due to the increased mass and system complexity over solar panels.

While these instruments will characterize a small fraction of the martian surface in great detail, the majority of the martian surface will likely never be explored and examined at the scales possible from lander and Rover data. Complementary techniques from orbit and at lander scales can allow for the extrapolation of the findings from landers to the rest of the planetary surface. To date, the TES, [22] and mini-TES [4] instruments are the best-matched set of complementary (spectral sampling and wavelength range) instruments sent to both the orbit and the surface of Mars. However, the scales of these measurements are quite disparate, where mini-TES samples outcrop scale variability (centimeter to meter spot sizes) and TES samples regional scale variability $(\sim 3 \times 8 \mathrm{~km}$ spots when the instrument is nadir looking).

\section{B. Vibrational Spectroscopy}

Vibrational spectroscopy, e.g., mini-TES, TES, Thermal Emission Imaging System (THEMIS, [23]), Compact Reconnaissance Imaging Spectrometer for Mars [24], and Observatoire pour la Minéralogie, l'Eau, les Glaces, et l'Activité [25], is commonly utilized to quantitatively determine mineralogical properties of observed materials on planetary bodies. Vibrational spectroscopy is based on the principle that energy is emitted/reflected at specific frequencies related to the vibrational motions of the material's crystal lattice, which in turn are directly related to the crystal structure and elemental composition of the material in question [26,27]. Several methods of vibrational spectroscopy are commonly utilized in remote sensing, including infrared emission and reflectance, near-infrared reflectance, Raman, and attenuated total reflectance spectroscopy. For most geologic materials, fundamental vibrational frequencies typically occur in the infrared $(\sim 2-100 \mu \mathrm{m})$ range of the electromagnetic spectrum, making the use of thermal infrared emission spectroscopy highly applicable to the examination of planetary surfaces, due to its low power constraints and relatively simple measurement technique (interferometry). These techniques have been used extensively $[27,28-33]$ to investigate the properties of rock-forming minerals in the laboratory and properties of planetary surfaces from orbit and landed spacecraft.

Thermal emission spectroscopy is typically a bulkanalysis method, as most rocks and surfaces are not homogenous at the spot size that typical instruments are capable of measuring (typically $\sim 0.5-1 \mathrm{~cm}$ diameter spot for laboratories). However, the measurement of materials in a laboratory is not currently the primary case where emission spectroscopy is used. 
In general, emission spectroscopy is used in remote sensing applications on planetary bodies and Earth with typical instruments, (e.g., THEMIS, TES, advanced spaceborne thermal emission and reflection radiometer (ASTER) [34]), having spot sizes or spatial sampling of hundreds of meters to kilometers [31,35-38]. At this scale, there is no compositionally/ mineralogically uniform surface; rather, endmembers in the thermal infrared spectral range (e.g., 6$100 \mu \mathrm{m}$ ), to first-order, add linearly with aerial abundance [39]. It is possible to use a linear unmixing model $\overline{\text { for }}$ thermal infrared emission spectroscopy, where an endmember library of pure minerals $[40,41]$ is used as a reference to determine quantitative mineral abundances based on their respective contributions (using a linear least squares method) to the measured spectrum. This method has been used extensively in the laboratory to determine the bulk compositions of unknown samples [42] and on spacecraft data to characterize the composition of Earth and other planetary bodies, including Mars [31,36,43-45].

However, this method is not without problems, as it is dependent on the mineral phases available in the endmember library spectra, meaning if the endmember is not in the library it cannot be included in the modeled spectrum. This leads to difficulties in the interpretation of mineralogically complex surfaces as the primary silicate absorption features related to the stretching of $\mathrm{Si}$ and $\mathrm{O}$ occur from $\sim 8$ to $14 \mu \mathrm{m}$. Furthermore, not every possible mineral has an easily accessible pure component that can be measured in the laboratory to make up a diverse and comprehensive endmember library (e.g., pigeonite). Further complicating matters, spectral features vary as solid solution series minerals vary in composition, so oftentimes a range of compositions is needed for individual minerals like olivine, where the major spectral absorptions move to either higher or lower wavelength as a function of forsterite number [e.g., 45,46].

A large body of work has been complete to interpret and quantitatively analyze thermal emission spectra, from unmixing spectral endmembers for quantitative mineral abundance determination to studying the effects of particle size and porosity on spectra $[32,39,47,48]$. This measurement technique is highly valuable and spacecraft missions that carried emission spectrometers have yielded a wealth of quantitative mineralogical data of the surface of Mars $[10,30,31,43,49]$. However, this work often lacks direct petrographic context for samples in question, which can significantly aid in determining the geologic mode of origin and type of alteration the samples have undergone. Instead, inferences about the nature of materials must be made from other instruments and techniques including such optical microscopy [3] , high-resolution morphology, and grain size information determined from thermal inertia data [50].

\section{Microscopic Emission Spectroscopy}

In this work, we present the design and implementation of a laboratory microscopic emission and reflectance spectrometer with the aim to bridge the gap between remote sensing and in situ techniques. Furthermore, the laboratory instrument has been mated with an existing mini-TES flight-spare instrument using the same microscopic fore optic and performs comparably to the laboratory setup with the commercially available spectrometer.

The microscopic laboratory instrument presented here has a spot size of $\sim 85 \mu \mathrm{m}$, a factor of $100 \times$ better than currently available instruments, and operates at roughly the scale of individual mineral phases in a medium grained volcanic sample. This small scale spot size allows for not only the reduction of spectral mixing in samples, reducing the need to perform linear deconvolution with large numbers of end members, but also will allow for in situ laboratory measurements of individual grains while retaining geological and spatial context of the sample under examination.

This technique can also help scale some of the other measurements that are typically made in the laboratory, on a lander, and from orbit. For example, it will be possible to better quantify how individual spectra observed in a single scene combine together to form a bulk rock spectrum and subsequently how bulk rock spectra relate to bulk planetary surface spectra from orbit. Currently, the spectral behavior of individual mineral grains as related to bulk rock and planetary surface spectra is not well constrained. This new instrument allows for the further characterization and quantification of bulk emission spectroscopy measurements.

One of the most significant advantages of this type of instrumentation is the extremely limited sample preparation required. This instrument is a noncontact measurement, requires no sample grinding or powdering, and can directly measure natural surfaces in place. When paired with a tool to remove the outermost rock rind, such as the rock abrasion tool on the MERs, this instrument could characterize the primary mineralogy of the sample. When the minimal sample preparation is combined with the relatively quick acquisition times $(\sim 5-10 \mathrm{~min}$ per spot), this instrument has significant advantages over techniques that take hours to days to measure a single sample. These advantages make this instrumentation a good candidate for in situ mineralogical studies on planetary surfaces, where it would be equipped on lander and/or Rover-style spacecraft. It should be possible to reduce the form factor of this instrument sufficiently to mount this instrument on a rover arm, much like the APXS and MB instruments of MER.

\section{Instrumentation and Experiment Apparatus}

We present the instrument design and implementation that allows for the automated acquisition of thousands of emission spectra with an instrument resolution of $\sim 85 \mu \mathrm{m}$ over a specified sampling area. In this section, we present all the components necessary to make the measurements at this scale. 
A labeled three-dimensional model that precisely describes the locations of every component is presented as Fig. 1. Additionally, the details for each additional component are available in Table 1 .

\section{A. System Components}

\section{Spectrometer}

A commercially available interferometric spectrometer supplied by ThermoFisher/Nicolet is used as the base for this instrument (Fig. 1 and Table 1). The spectrometer is originally intended to be used as a transmission spectrometer, though with the removal of a cover port and an internal mirror, the instrument can collect light from outside its environmental housing. The spectrometer purchased is equipped with a cesium iodide (CsI) beamsplitter with an operating range of $6400-200 \mathrm{~cm}^{-1}$ (Table 1) and operates as a Michelson Interferometer; the beamsplitter directs and recombines light from both a fixed and precisely controlled moving mirror where signals are recombined to create a constructive and deconstructive interference pattern. After the light is modulated it is directed to either a pyroelectric or quantum detector. The modulated energy - in the form of an

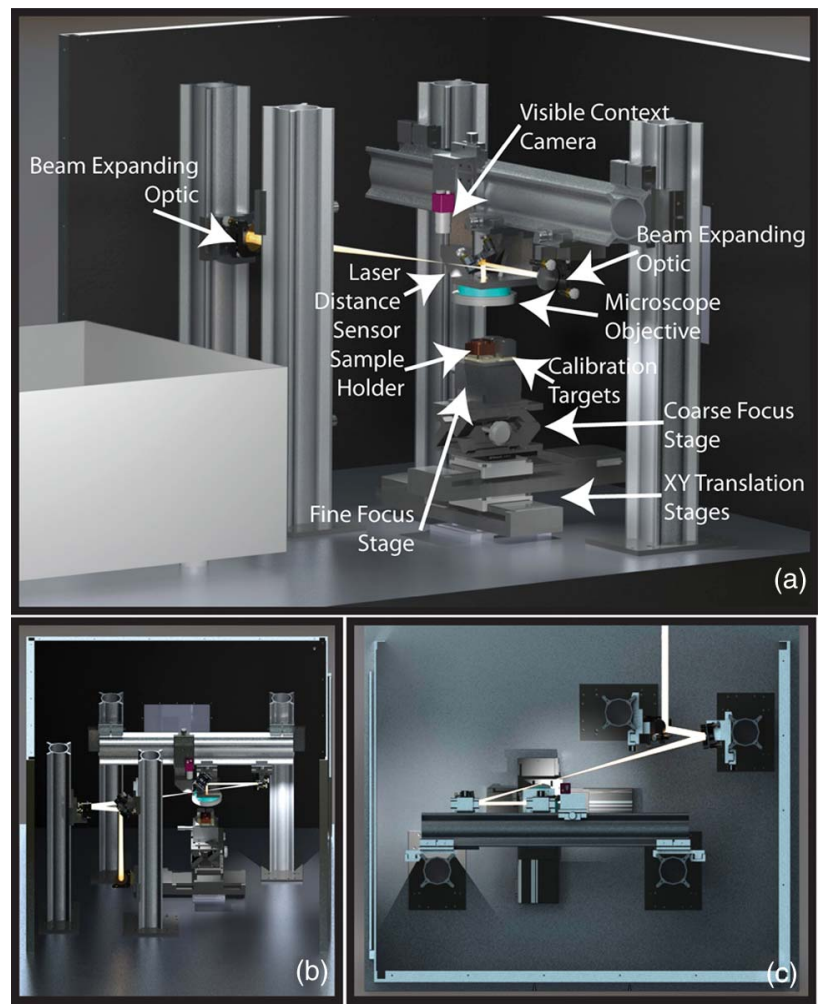

Fig. 1. (Color online) Three rendered views of the instrument CAD model where major components are labeled in Fig. 1(a). (a) A perspective view where the microscope objective is shown in blue and the ray trace of the extreme rays is shown in yellow. The top and side enclosing walls of the environmental chamber have been removed from this drawing. (b) Side view of the instrument where additional components, including the relay optics that direct the beam into the spectrometer, can be observed. (c) Topdown view of the instrument optical path where the beam entering the spectrometer leaves toward the top of the image. interferogram with intensity related to moving mirror position [Fig. 2(a)]-is converted to an uncalibrated power spectrum [Fig. 2(b)] by a discrete Fourier transform.

\section{Infrared Detectors}

In this setup, we utilize two separate detectors depending on the type of measurement the user wishes to make. We have implemented both a mercury cadmium telluride (MCT) quantum detector and deuterated $L$-alanine doped triglycene sulfate (DLaTGS) pyroelectric detector in this system. While the pyroelectric detector is comparable to what is currently utilized on many spacecraft interferometers (e.g., TES, mini-TES), it has a sensitivity of $\sim 5$ to $10 \times$ lower than the cryogenically cooled MCT quantum detector. However, adding a cryogenically cooled detector to spacecraft instruments adds significant cost, complexity, mass, and power consumption and increases the potential for detector failure if the cooler ceases to operate. Furthermore the spectral range covered by the MCT detectors is often limited to $\sim 600 \mathrm{~cm}^{-1}$, though they can measure to lower wavenumbers using special coatings but with reduced signal-to-single noise (SNR). These longer wavelengths $(>20 \mu \mathrm{m})$ often provide valuable and diagnostic absorption features for primary mafic and secondary alteration mineralogy $[45,46,51]$ and are important for mineralogical studies of planetary surfaces.

In this instrument setup, we utilize the MCT detector as a quick reconnaissance tool to evaluate the mineralogical diversity of the sample in a laboratory setting over its limited wavelength range and then utilize the pyroelectric DLaTGS detector to collect the full spectral range allowable by the beamsplitter and optics combination. In addition, the pyroelectric detector is a better match for the capabilities and performance that can be expected for this style of instrument on a planetary surface.

\section{Optical Design}

The optical design of the system is straightforward, utilizing a collimated beam throughout the system (Fig. 3). The microscope is a diamond turned Schwarzchild objective with an $F$-number of $\sim 0.4$ and a focal length of $9.81 \mathrm{~mm}$ (Fig. 4, Table 1). This objective minimizes spherical aberration, coma, and astigmatism as the primary and secondary surfaces are matched spherical components. Depending on the position of the secondary mirror, it is possible to manipulate the nature of the light exiting the optic. For example, in the version mounted to the flight spare mini-TES instrument, a back $F$-number of 12 is used as it matches the original design of the mini-TES Cassegrain telescope [4].

However, for the laboratory setup, the position of the secondary mirror was adjusted so the microscope objective (Fig. 4 ) outputs a collimated beam $\sim 1 \mathrm{~cm}$ in diameter, which is upsized by beam expanding optics to $\sim 2 \mathrm{~cm}$ in diameter to better match the desired 
Spectrometer

Spectrometer manufacturer

Interferometer type

Beamsplitter material

Typical spectral range

Spectral sampling

Samples / interferogram

Interferometer beam size
ThermoFisher/nicolet

Michelson

Cesium iodide (CsI)

4000-200 $\mathrm{cm}^{-1}$

$1-16 \mathrm{~cm}^{-1}$

8192

$\sim 2.5 \mathrm{~cm}$ (through beamsplitter)

Detectors

DLaTGS detector

Temperature control

Detector size

Detector $D^{*}$

Interferometer mirror velocity

Spectral range

\section{MCT-B}

Temperature control

Detector size

Detector $D^{*}$

Interferometer mirror velocity

Spectral range
Thermo-electric temperature stabilized

$0.5 \mathrm{~mm}$ diameter

$>2.4 \times 10^{8} \mathrm{~cm} \cdot \mathrm{Hz}^{1 / 2} \cdot \mathrm{Watt}^{-1}(20 \mathrm{~Hz})$

$0.1581 \mathrm{~cm} / \mathrm{s}$

$6400-200 \mathrm{~cm}^{-1}$

Cryogenic liquid nitrogen cooled

$1 \mathrm{~mm}$ by $1 \mathrm{~mm}$ square

$>8.0 \times 10^{9} \mathrm{~cm} \cdot \mathrm{Hz}^{1 / 2} \cdot \mathrm{Watt}^{-1}(20 \mathrm{~Hz})$

$1.8988 \mathrm{~cm} / \mathrm{s}$

$11,700-400 \mathrm{~cm}^{-1}$

Fore-optics

Microscope objective design

Spot size

Numerical aperture/f-number

Microscope field of view

Working distance

Depth of field

Sample/calibration specifics

Maximum sample size

Sample temperature

Calibration blackbody targets

DLaTGS SNR (5 min acq., @380 K, $10 \mu \mathrm{m}$ )

MCT-B SNR (5 min acq., @380 K, $10 \mu \mathrm{m}$ )

Silicon nitride infrared source

Schwarzschild objective

$\sim 85 \mu \mathrm{m}$ (approaching diffraction limit)

$0.8 / \sim 0.4$

$120^{\circ}$

$\sim 9.81 \mathrm{~mm}$

$\sim 20 \mu \mathrm{m}$

Supporting systems

$X$ Stage translation

$Y$ Stage translation

$Z$ Stage translation

Coarse $Z$ stage translation

$X-Y-Z$ Stage microstep size

Laser displacement sensor resolution (Z)

Context camera (1.5 Megapixels)
$2 \times 2 \mathrm{~cm}$

Heated to $100 \mathrm{~K}>$ ackground

(1) "hot" $400 \mathrm{~K}$, (1) "warm" $280 \mathrm{~K}, 5 \mathrm{~mm}$ spherical blackbody cavity $\mathrm{w} / 0.5 \mathrm{~mm}$ diameter entrance

$\sim 80$

$\sim 120$

$>1200^{\circ} \mathrm{K}$ for reflectance mode input of the Nicolet spectrometer. The relay/beam expanding optics are a pair of matched spherical mirrors with focal lengths of 75 and $150 \mathrm{~cm}$ also designed to minimize spherical aberration, coma, and astigmatism to ensure the image formed on the detector is crisp and accurately represents a small circular spot measured on the sample. Several other flat fold mirrors are utilized to direct the beam from the high measurement location to optical table level spectrometer. All mirrors in the system are gold coated and flat to one-fourth wavelength in the visible wavelengths, making them excellent reflectors in the infrared, with reflectivity $>0.995$ over nearly the entire spectral range [52]. Furthermore, in principle the optical design of this system is quite similar, with the exception of the microscope objective and the relay optics required to achieve the $\sim 85 \mu \mathrm{m}$ measurement spot size, to that of a suite of existing emission spectrometers used extensively by the planetary science community to evaluate and characterize data returned from spacecraft missions $[29,31,37,38,41,42,45,53-56]$.

Once the collimated energy is directed into the Nicolet spectrometer by the last fold mirror, the energy passes through a CsI beamsplitter oriented at $45^{\circ}$ (Fig. 3), which equally separates the light into 

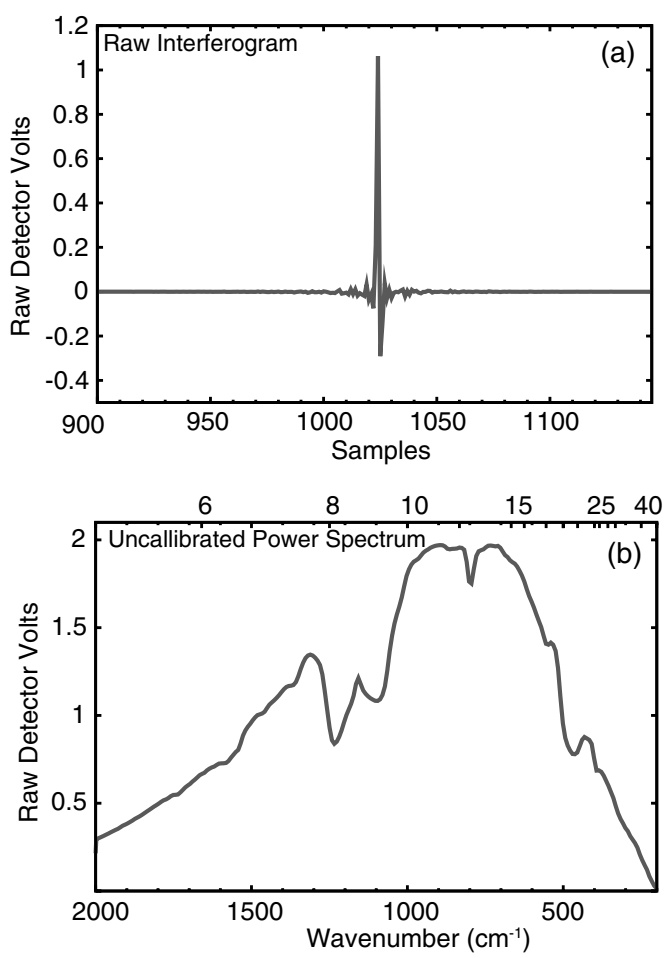

Fig. 2. (a) Raw interferogram generated from a $\sim 85 \mu \mathrm{m}$ spot is shown along with the raw uncalibrated power spectrum of quartz. (b) The data in each plot are related to one another by a discrete fast Fourier transform. The power spectrum of two known blackbody targets is then used to calibrate the data from this instrument in a full aperture calibration to radiance with units of $\mathrm{W} \mathrm{cm}{ }^{-2} \mathrm{sr}^{-1}$ (Section 2.B).

two directions with different path lengths, one fixed and one variable. The specifics of Michelson interferometry are described in Section 2.A.1. However, this signal measured by the detector is not purely derived from the sample. We use a full aperture calibration (described below) that accounts for the instrument response function as well as radiance contributed by the instrument itself [42]. Furthermore the environment is also emitting, and a portion of that energy is reflected off of the sample and captured by the optical system, also known as downwelling radiance [42]. The specifics of instrument calibration are discussed in Section 2.B.

\section{Supporting Systems}

A variety of support systems is required for the acquisition and calibration of spectral data at the sub-100 $\mu \mathrm{m}$ scale (Figs. $\underline{1}$ and $\underline{5}$, Table $\underline{1}$ ). In order to accurately measure a spectrum, we must control the $X, Y$, and $Z$ position of the sample to within $\sim 1-2 \mu \mathrm{m}$ with little or no physical movement of the sample. To do this we use translational stages capable of high precision movement.

Because of the extremely fast (small depth of field) Schwarzschild objective, it is necessary to position the sample within $\sim 20 \mu \mathrm{m}$ of the best focus in the $z$ axis. To accomplish this, we use a laser displacement sensor capable of accurately and precisely measuring distances to within several micrometers.

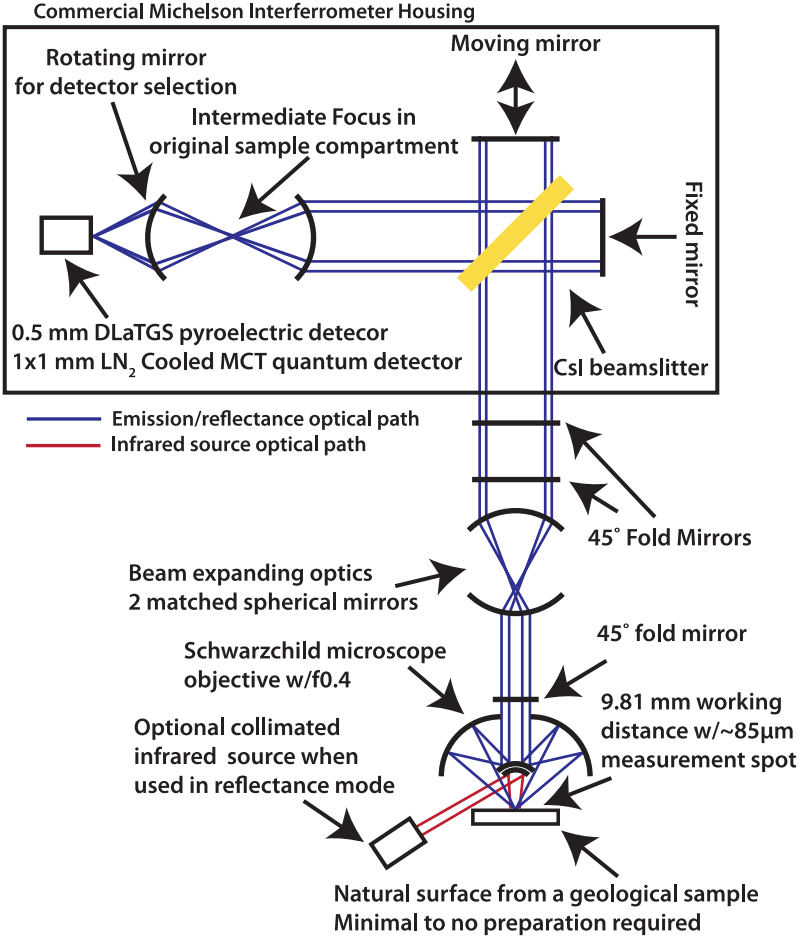

Fig. 3. (Color online) Schematic layout of the optical system for the microscopic emission and reflectance spectrometer represents all the major components of this optical system. The blue lines represent the extreme light rays of the spectrometer optical system, where the relative size of the rays represent the true scaling and path of the light in the system. The black shapes represent different optical mirrors or system components in the system and are labeled accordingly. The red lines represent the emitted energy of the infrared source when the system is used in reflectance mode. Note: No lenses were used in this system and all optical components are mirrors. The layout of the system was simplified for this figure.

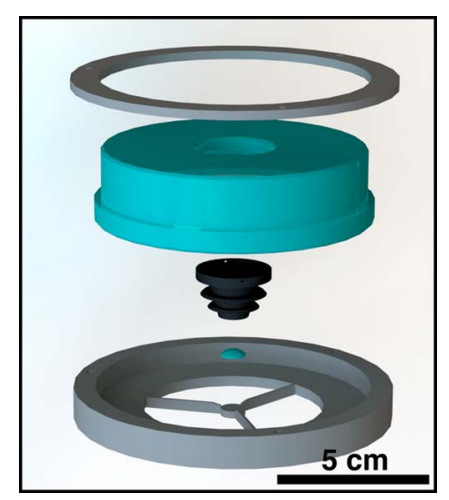

Fig. 4. (Color online) Expanded view of the solid model of the Schwarzschild objective is shown in this figure. The blue components represent diamond turned optics, while the silver components are the supporting spider and compression ring used to physically locate and hold the secondary mirror (small convex surface). The objective is mounted onto a specialized mounting bracket using a three-point mount directly to the primary mirror (large concave surface). Additionally, a baffle (black) designed to minimize stray light is mounted at the exit of the primary mirror and extends into the primary mirror cavity with a maximum light allowance diameter matched to the secondary mirror. 


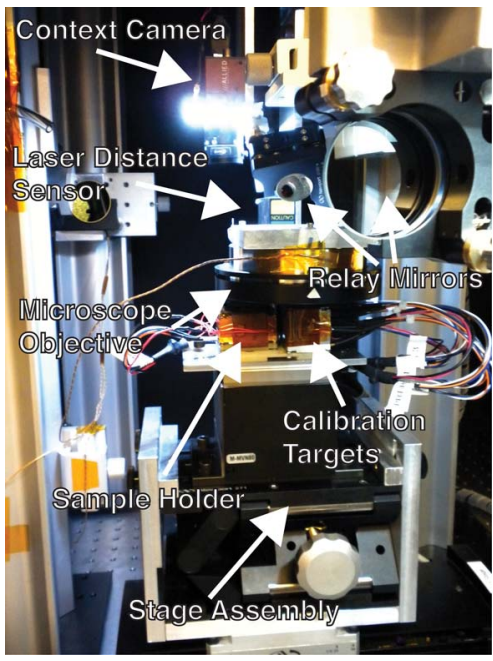

Fig. 5. (Color online) Side view of the $X Y Z$ position system, microscope objective, and supporting systems, including the laser range displacement sensor and the context camera. For reference, the relay mirrors are 2 inches in diameter.

The desired sample spot is moved under this sensor and the $Z$ stage is moved until the best focus is established, generally within 3-5 $\mu \mathrm{m}$ [Figs. 6(a) and 7(a)]. This system works well for both solid and particulate samples. Where a best focus cannot be found (due to low reflectivity, oriented crystal faces that prevent the return of a laser signal to the sensor detector, etc.), the location is recorded and the previous best focus is used. This assumption is generally reasonable where the sample is not a particulate and the surface is generally smooth over the data spacing. When this is not the case, a spectrum of a defocused (and enlarged spot) is acquired.

A visible imaging context camera with $\sim 7 \mu \mathrm{m} /$ pixel resolution is also used to identify desired measurement locations [Figs. 6(b) and 7(b)] and control the acquisition grid. This grid can be constructed as any combination of $X$ by $Y$ samples and calibration
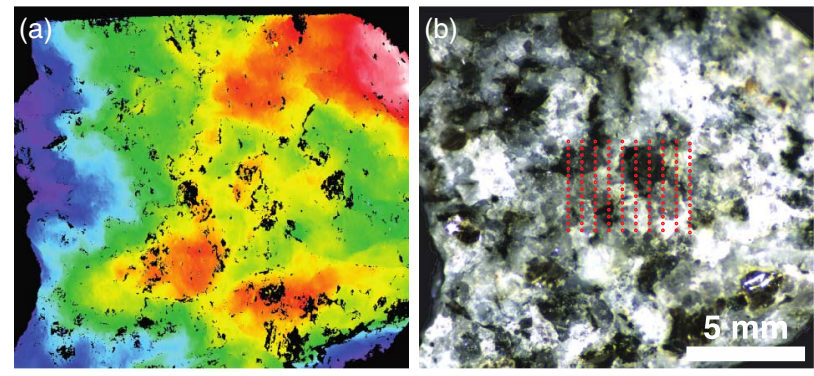

$0 \mathrm{~mm}$ $3.441 \mathrm{~mm}$

Fig. 6. (Color online) (a) Example of a microtopography map of a solid sample used to find the microscope focal point within $\sim 5 \mu \mathrm{m}$. Black locations indicate the absence of good laser returns. In these cases, we use an interpolated value for best focus. (b) Coaligned visible context image with a microscope sampling pattern overlain (red circles). The circles are to scale with the spot size of the instrument and are the exact locations where thermal emission data are acquired.
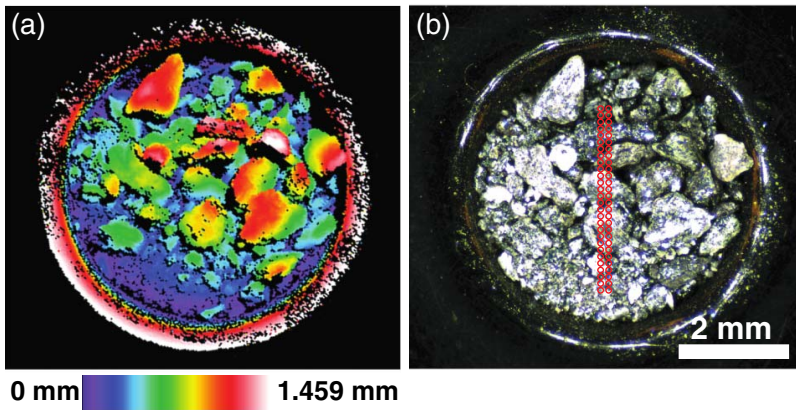

Fig. 7. (Color online) (a) Example of a microtopography map of a particulate sample used to find the microscope focal point within $\sim 5 \mu \mathrm{m}$. Black locations indicate the absence of good laser returns. In these cases we use an interpolated value for best focus. (b) Coaligned visible context image with a microscope sampling pattern overlain (red circles). The circles are to scale with the spot size of the instrument and are the exact locations where thermal emission data are acquired.

targets may be acquired at any interval, though generally at the end of a column of measurements.

These $X, Y$, and $Z$ translation stages were physically referenced to each test location (context image, focus, and microscope) by a thin wire $(\sim 35 \mu \mathrm{m}$ in diameter) cross hair that can be heated to $\sim 600 \mathrm{~K}$ to reference the spectrometer with a high level of signal at the detector. Once each test position has been established in relational space, it is possible to accurately move to each test position with a sample and measure the identical spot to within $\sim 5 \mu \mathrm{m}$ in absolute position, which is less than the individual pixel size of the context imager.

The sample in the emission setup is heated above room temperature to enhance signal to noise for individual measurements [42]. While this process can result in the dehydration of some clays and sulfates, in general most rock forming minerals do not significantly change their crystal structure with a moderate $\left(100^{\circ} \mathrm{K}\right)$ increase in temperature. Furthermore, it is not uncommon for geologic materials, especially on airless bodies, to experience temperatures above $350 \mathrm{~K}$ [57]. While it is not explicitly necessary to heat the sample to $\sim 390 \mathrm{~K}$, it aids in reducing measurement time and significantly increases the signal to noise, as emitted radiance is proportional to temperature to the fourth power. However, as an alternative to heating samples, we have developed a thermal infrared reflectance mode for this instrument (Section 2.A.5).

Two blackbody cavities $(\overline{5 \mathrm{~mm}}$ spheres with a $0.5 \mathrm{~mm}$ entrance) are used as targets for the instrument's full aperture calibration (Fig. 8). These blackbodies are controlled to $\sim 0.1 \mathrm{~K}$ precision and accuracy at 400 and $380 \mathrm{~K}$, bracketing the typical temperature $(\sim 390 \mathrm{~K})$ of a sample in this instrument. These calibration targets are mounted directly next to the sample holder, which allows for multiple calibration points throughout the measurement to capture any instrument drift or changes in the environment. The calibration targets are instrumented with two platinum resistance thermistors (PRTs) 
(a)

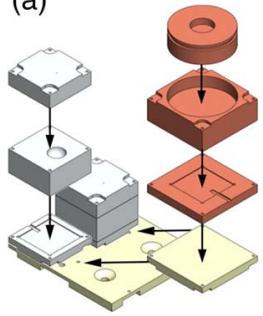

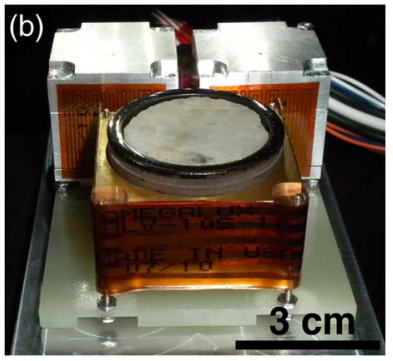

Fig. 8. (Color online) Model of the sample holder (orange) and blackbody calibration targets (gray), (a) with the individual components expanded for clarity. The sample holder is constructed of copper because of its extremely high thermal conductivity, while the blackbodies are constructed of aluminum because aluminum has a high reflectivity over the thermal infrared wavelength region and any unpainted surfaces will reflect the majority of the incident energy. (b) The final completed sample holder and blackbody calibration targets with a quartz standard used to compare the instruments calibration to existing laboratory equipment.

each (one above and below the spheres) and allow the precise determination of the temperature of the sphere. The two PRTs per blackbody typically show a measured temperature difference across a sphere of $0.05 \mathrm{~K}$, which is significantly below the accuracy and precision of the PRTs. This implies an isothermal measurement as the PRTs have an absolute calibration accuracy of $\sim 0.1 \mathrm{~K}$ from 90 to $780 \mathrm{~K}$.

Finally, an instrumented environmental chamber (Fig. 1), where water vapor and $\mathrm{CO}_{2}$ have been scrubbed from the atmosphere, encompasses the entire instrument. The interior of this chamber is painted with Krylon Ultra Flat Black 1602 paint that has an emissivity $>0.95$ over the entire thermal infrared wavelength region [58]. We monitor relative humidity, environmental air temperature, and the temperatures of various system components. Any dramatic changes in these parameters are logged throughout the acquisition of sample data and can be used to identify data that may be poorly calibrated.

\section{Reflectance Mode}

As an alternative to directly heating the sample to $>100 \mathrm{~K}$ above ambient temperature, we have developed a microreflectance attachment for this instrument (Fig. 3, Table 1). In this case, rather than the sample being heated from below, the sample is illuminated by an infrared source $\left(\mathrm{a}>1200^{\circ} \mathrm{K}\right.$ silicon nitride emitter) with relatively uniform spectral response over 2000 to $200 \mathrm{~cm}^{-1}$. While this is not the primary mode of this instrument, as the goal is to make direct comparisons to existing laboratory and spacecraft data, it is a unique measurement that could easily be applied to a landed spacecraft thermal infrared microspectrometer.

While commercial microscopic reflectance instruments are available, they typically use cooled detectors and modulate the light (which occurs when light passes through the interferometer) prior to its interaction with the sample. The experimental emission spectroscopy microscope setup we present here is not available commercially and the reflectance setup developed is significantly different than any commercially available instrument. Differing significantly from commercially available reflectance instruments, this reflectance instrument setup uses unmodulated light from an infrared source directed at the sample in a nearly perpendicular orientation. This light is then reflected off the sample approximately into a hemisphere for Lambertian surfaces, which is expected as typical geologic surfaces do not highly forward- or back-scatter. This unmodulated reflected light is captured by the same optical system that captures the emitted energy when the sample is directly heated. The value of this method is that both an emission and reflectance measurement can be made of the identical spot. If different fore-optics were utilized with this system (an offaxis parabola or Schwarzschild objective with a larger $f$-number), the reflectance mode can be used to quickly acquire high SNR microspectra while a defocused spot can be utilized to make bulk emission measurements. The variety of measurements (atmospheric measurements, point counting of individual mineral grains retaining primary geologic context, and bulk mineralogy measurements at the outcrop scale) makes this style of instrumentation unique in its capabilities and a strong candidate for a rover or lander platform as a quantitative mineralogy instrument.

\section{B. Calibration and Data Acquisition}

\section{Automated Acquisition}

The microscopic emission spectrometer allows the investigator to easily acquire large volumes of spectroscopic data with little input. The investigator defines the acquisition parameters, including number of spots in the $X$ and $Y$ directions [Figs. 6(b) and 7(b)], the spacing between these spots, the sample and blackbody calibration target temperatures, and the calibration interval. Once the sample is loaded, the system automatically acquires all the specified data and necessary ancillary measurements including temperature of the environmental chamber, relative humidity, instrument temperature, and sample temperature. In order to ensure measurement stability, several parameters, including sample and blackbody temperatures, relative humidity, and microscope temperature, are monitored until they reach the set points. Furthermore, anytime the sample is moved a significant distance (e.g., to the calibration targets), the instrument pauses until stability conditions are met (typically $5 \mathrm{~min}$ ).

\section{Spectral Calibration}

The calibration of raw data to emissivity has not been significantly modified from [42] and the majority of the equations and measurements necessary to accurately account for all the factors that affect thermal emission have been presented previously, including the energy related to sample emission, reflection, and background sources [42,59,60-62]. 
The major difference between the method used by Ruff, Christensen, Barbera, and Anderson [42] and the method described here is the use of numerous blackbody calibration measurements over the span of the entire spectral acquisition. Depending on the number of acquisition points the investigator specifies for the microscopic emission spectrometer ( $>200$ to 1000), lengthy ( $>1$ day) measurements can arise, necessitating the use of multiple blackbodies to account for changes in the instrument response and environmental parameters. Here we present the updated method for calibration of thermal emission data acquired from this instrument.

After Christensen and Harrison [62] and Ruff, Christensen, Barbera, and Anderson [42], we use the following equations to solve for the emissivity of the sample, accounting for a time-varying term using a cubic spline interpolation for each spectral point with a sample at an unknown temperature (definitions for all variables used can be found in Table 2). We do not show the cubic spline interpolation in the following equations but rather include the solutions for all equations at wavelengths $\lambda$, temperature $T$, and time $t_{\mathrm{samp}}$, where the values at each time have been interpolated with the cubic spline or a linear approximation if enough data points are not available for cubic interpolation. This equation set derives a temperature independent emissivity using a time-interpolated calibration, though throughout it is useful to consider the idealized and temperature dependent spectral radiance $(B)$ and emissivity $(\varepsilon)$ as inseparable. These variables are generally represented as $\varepsilon(\lambda) B\left(\lambda, T, t_{\text {samp }}\right)$ and

Table 2. Definition of Variables Used in the Equations to Derive Calibrated Emissivity

\begin{tabular}{ll}
\hline$\lambda$ & Wavelength \\
$T$ & Temperature \\
$t_{\text {samp }}$ & Time at a given point between two \\
& calibration measurements when the sample \\
& was acquired. The corresponding function \\
& value is calculated using a cubic spline. \\
$\varepsilon_{\text {inst }}$ & Emissivity of the instrument \\
$B_{\text {inst }}$ & Idealized radiance of the instrument \\
$F$ & Instrument response \\
$\varepsilon_{\text {env }}$ & Emissivity of the environment \\
$B_{\text {env }}$ & Idealized radiance of the environment \\
$\varepsilon_{\text {samp }}$ & Emissivity of the sample \\
$B_{\text {samp }}$ & Idealized radiance of the sample \\
$R_{\text {samp }}=1-\varepsilon_{\text {samp }}$ & Reflectivity of the sample is equivalent to \\
$V_{\text {samp }}$ & 1-emissivity by Kirchhoff's law \\
$B_{\text {bb }}$ & Measured sample voltage \\
$V_{\text {bb }}$ & Idealized radiance of the blackbody \\
$c f$ & calibration targets \\
$\sigma_{V}$ & Measured blackbody voltage \\
$S N R$ & Christiansen feature wavelength \\
$n$ & Standard deviation of detector voltage \\
$h$ & Signal to Noise \\
$k$ & Number of spectral coadditions \\
& Planck's constant \\
& Speed of light \\
& \\
& Boltzmann's constant \\
\hline &
\end{tabular}

are typically manipulated as a group, until the final derivation of emissivity.

First, we take the initial equation from Christensen and Harrison [62] that defines all the important parameters that contribute to the measured voltage of the Fourier transform spectrometer:

$$
\begin{aligned}
& V_{\text {meas }}\left(\lambda, T, t_{\text {samp }}\right) \\
& \quad=\left[\begin{array}{l}
\varepsilon_{\text {samp }}(\lambda) B_{\text {samp }}\left(\lambda, T, t_{\text {samp }}\right) \\
+R_{\text {samp }}(\lambda) \varepsilon_{\text {env }}(\lambda) B_{\text {env }}\left(\lambda, T, t_{\text {samp }}\right) \\
-\varepsilon_{\text {inst }}(\lambda) B_{\text {inst }}\left(\lambda, T, t_{\text {samp }}\right)
\end{array}\right] F\left(\lambda, t_{\text {samp }}\right) .
\end{aligned}
$$

By using blackbodies at two known and temperatures and raw voltages measured by the detector for each calibration target, we can compute an instrument function [42,63] [Fig. 9(a)]. Equation (2) assumes that the emissivity of the blackbodies is

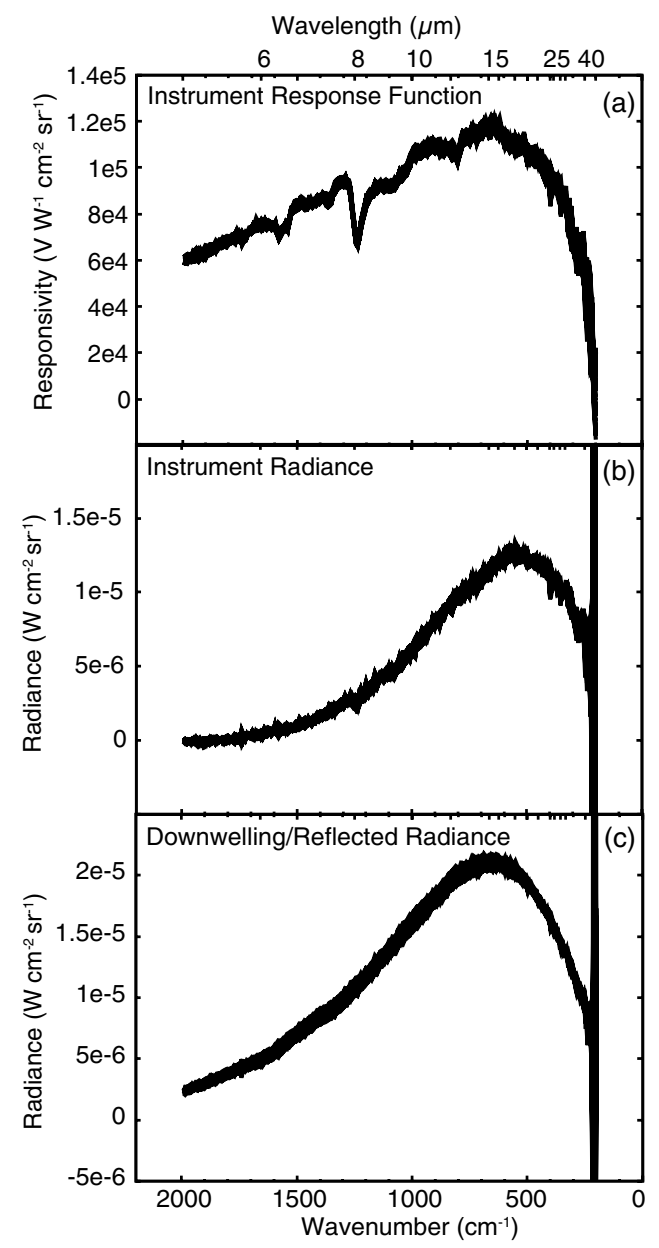

Fig. 9. Typical instrument calibration and response parameters are shown. (a) Twenty-five different instrument response functions over 10 days. (b) Twenty-five different instrument radiance curves over 10 days. (c) Twenty-five different down welling radiance measurements over 10 days. The variability in all cases is less than a few percent. In order to help capture changing environmental conditions, the instrument response function and instrument radiance are interpolated for each sample using cubic-splines based on the sample acquisition time. 
1 at all wavelengths and there is no reflected component. The time-varying instrument response function is a critical component to the calibration procedure, as it allows for the conversation of uncalibrated volts measured by the detector to calibrated spectral radiance $\left(\mathrm{W} \mathrm{cm}-2 \mathrm{sr}^{-1}\right)$. Additionally, the time-varying component allows for small changes in the instrument behavior to be captured during long data acquisition runs:

$$
F\left(\lambda, t_{\mathrm{samp}}\right)=\frac{V_{\mathrm{bb}}\left(\lambda, T_{1}, t_{\mathrm{samp}}\right)-V_{\mathrm{bb}}\left(\lambda, T_{2}, t_{\mathrm{samp}}\right)}{B_{\mathrm{bb}}\left(\lambda, T_{1}, t_{\mathrm{samp}}\right)-B_{\mathrm{bb}}\left(\lambda, T_{2}, t_{\mathrm{samp}}\right)} .
$$

Equation (3) is the derivation of the instrument radiance term [Fig. 9(b)]. Using Eq. (2) and a single blackbody measurement, it is possible to derive the instrument radiance. The instrument radiance is the energy that reaches the detector that did not originate at the sample [42], including detector and background energy from the emitting components inside the spectrometer. As a further simplification, the instrument emissivity $\left[\varepsilon_{\text {inst }}(\lambda)\right]$ is commonly assumed to be 1 and the instrument radiance term is replaced by an ideal blackbody of the measured instrument temperature [42]; however, in the case of this instrument we use the derived instrument radiance and not an ideal radiance, as the instrument radiance is a combination of blackbodies of several temperatures for this instrument:

$$
\begin{aligned}
& \varepsilon_{\text {inst }}(\lambda) B_{\text {inst }}\left(\lambda, T, t_{\text {samp }}\right) \\
& =\frac{B_{\text {inst }}\left(\lambda, T_{1}, t_{\text {samp }}\right)-V_{\text {bb }}\left(\lambda, T_{1}, t_{\text {samp }}\right)}{F\left(\lambda, t_{\text {samp }}\right)} .
\end{aligned}
$$

Calculating calibrated radiance for a sample is accomplished by rearranging Eq. (1) to the form shown in Eq. (4). In this case all of the radiance (both emitted and reflected) are moved to a single side of the equation. In order to simplify this equation and derive a temperature independent emissivity, it is necessary to determine the sample temperature from a noncontact method (as is typical for spacecraft missions) [64]. In order to solve for temperature, we assume that over some portion of the spectrum the emissivity is 1 and the reflectivity is zero, which is best met at the Christiansen frequencies in the spectrum. This is the frequency where the index of such as the microscopic emission spectrometer where many environmental sources of a variety of temperatures are being reflected off of the sample, we use a diffuse gold reflector in place of a sample to accurately measure the typical downwelling/reflected spectral component [Fig. 9(c)]. In this case we then apply a scaled version of this measured downwelling radiance as the mixed variable group $\varepsilon_{\text {env }}(\lambda) B_{\text {env }}\left(\lambda, T, t_{\text {samp }}\right)$. This allows for spectral features present in the downwelling radiance as well as temperature variability to be accounted for robustly:

$$
\begin{aligned}
& {\left[\begin{array}{l}
\varepsilon_{\text {samp }}(\lambda) B_{\text {samp }}\left(\lambda, T, t_{\text {samp }}\right) \\
+R_{\text {samp }}(\lambda) \varepsilon_{\text {env }}(\lambda) B_{\text {env }}\left(\lambda, T, t_{\text {samp }}\right)
\end{array}\right]} \\
& =\left[\begin{array}{l}
\frac{V_{\text {samp }}\left(\lambda, T, t_{\text {samp }}\right)}{F\left(\lambda, t_{\text {samp }}\right)} \\
+\varepsilon_{\text {inst }}(\lambda) B_{\text {inst }}\left(\lambda, T, t_{\text {samp }}\right)
\end{array}\right] .
\end{aligned}
$$

If we calculate a brightness temperature for all radiances [Eq. (5), assuming there are no emissivity absorption features] for all wavelengths using the Planck equation in the form of Eq. (6), the maximum temperature of the sample temperature is likely the best match for the position of the Christiansen frequency. Ruff, Christensen, Barbera, and Anderson [42] includes a detailed discussion of the effect of deriving the wrong Christiansen frequency on the absolute calibration of spectral data. Though the effects are generally minimal in terms of absolute emissivity, they are not negligible:

$$
\begin{aligned}
& B_{\text {samp@cf }}\left(\lambda, T, t_{\mathrm{samp}}\right)= \frac{V_{\mathrm{samp} @ c f}\left(\lambda, T, t_{\mathrm{samp}}\right)}{F\left(\lambda, t_{\mathrm{samp}}\right)} \\
&+\varepsilon_{\text {inst }}(\lambda) B_{\text {inst } @ c f}\left(\lambda, T, t_{\mathrm{samp}}\right), \\
& T=\left(\frac{h c}{\lambda k}\right)\left(\frac{1}{\ln \left[\frac{2 h c^{2} \lambda^{-5}}{B_{\mathrm{samp} @ c f}}+1\right]}\right) .
\end{aligned}
$$

The final step for calibration is the calculation of a temperature independent emissivity. This is accomplished by again rearranging Eq. (1) using the time interpolated instrument response function, downwelling radiance, and instrument energy variables that were solved for in Eqs. (2) - ( $\underline{6})$ :

$$
\varepsilon_{\text {samp }}(\lambda)=\frac{\frac{V_{\text {samp }}\left(\lambda, T, t_{\text {samp }}\right)}{F\left(\lambda, t_{\mathrm{samp}}\right)}-\varepsilon_{\text {env }}(\lambda) B_{\text {env }}\left(\lambda, T, t_{\text {samp }}\right)+\varepsilon_{\text {inst }}(\lambda) B_{\text {inst }}\left(\lambda, T, t_{\text {samp }}\right)}{B_{\text {samp }}\left(\lambda, T, t_{\mathrm{samp}}\right)-\varepsilon_{\text {env }}(\lambda) B_{\text {env }}\left(\lambda, T, t_{\text {samp }}\right)} .
$$

refraction $(n)$ for the sample is equal to the index of refraction for the surrounding medium [65]. This frequency is often coincident with low extinction coefficients $(k)$ for geologic materials and produces an emissivity near 1.0 [42]. In a complicated system,
The validity of this method is well established and a detailed discussion and error analysis of many components of this calibration routine is performed by Ruff, Christensen, Barbera, and Anderson [42]. Furthermore, we utilize a full-aperture calibration, 
with the blackbody calibration targets placed at the same position as the sample. With this setup, the same number of components (e.g., mirrors, baffles, optomechanical components) and instrument orientation (e.g., field of view, sample/calibration target position) are used and allow for all of the components to contribute in the same way to the raw measured spectrum. These contributions are then incorporated into the instrument response function and instrument radiance, allowing them to be completely removed in the calibration routine with no assumptions about the reflectivity of various mirrors or contribution of other components required.

\section{Instrument Results}

\section{A. Signal-to-Signal Noise}

The signal to nose ratio of this system is dependent on several factors, including detector responsivity, the temperature of the target material, the number of spectra that are coadded together (scales as the square root of the number of samples), the spectral sampling, and the overall throughput of the optical system. In order to assess the SNR of a complicated optomechanical system, such as that presented in this work, we measure many individual spectra with no coadding of the same spot under the same conditions for each detector. We measured a quartz standard and each blackbody calibration target (Fig. 10). In order to calculate the SNR of the system, a moving window standard deviation of 20 spectra is divided by the instrument response function and averaged together. An ideal blackbody at the specified target temperature is then divided by the average windowed standard deviation [Eq. (8)]. The SNR is calculated in this manner, as this removes any timedependent variations in the instrument that may be due to temperature controller instability or a changing environment and instrument temperature:

$$
\operatorname{SNR}(\lambda, T)=\frac{B_{\text {samp }}(\lambda, T) F(\lambda, T)}{\left[\frac{1}{n} \sum_{i=1}^{n}\left(\frac{1}{20} \sum_{j=i}^{j+20} \sigma_{V}(\lambda, T)_{j}\right)\right]} .
$$

The derived instrument SNR at $900 \mathrm{~cm}^{-1}$ for the DLaTGS detector is $\sim 70$ to 90 for target temperatures ranging from 380 to $400 \mathrm{~K}$. The SNR at $900 \mathrm{~cm}^{-1}$ for the MCT-B detector is slightly higher at $\sim 100$ to 120 for target temperatures ranging from 380 to $400 \mathrm{~K}$. The increase in signal for the MCT-B detector is not the predicted $\sim 2$ to 3 times improvement expected, though this is likely due to the lack of a cold field stop that would prevent stray light and extreme rays from entering the detector. Since the noise of a DLaTGS is fixed with the area of the detector, it is not as affected by the stray light/ extreme rays of the system as the MCT-B detector that has noise that scales with the number of photons that interact with the detector. Thus, a warm instrument and environment, coupled with extreme rays

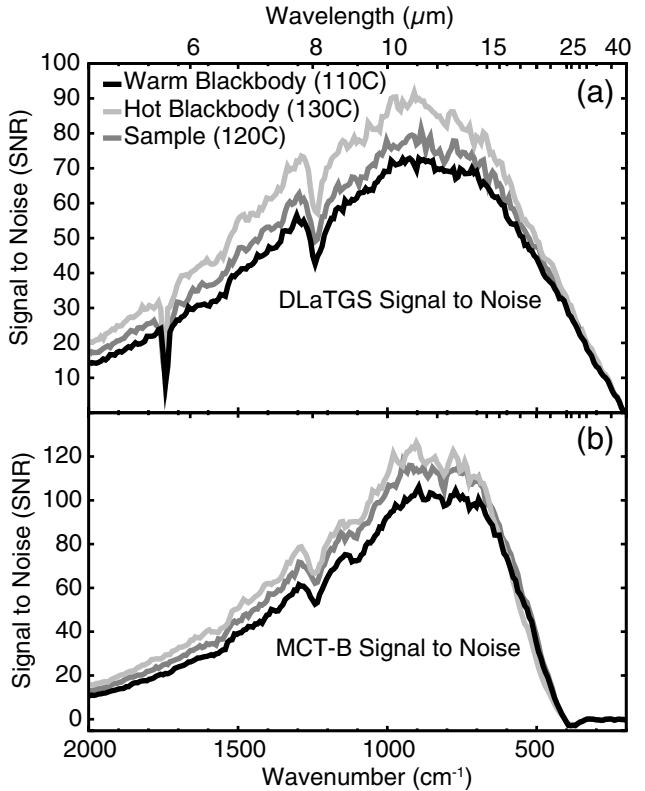

Fig. 10. Signal to noise for each detector in the microemission and reflectance spectrometer instrument. The SNR is shown for each of the blackbody calibration targets and a quartz sample. The SNR is directly correlated to sample temperature in all cases. In each case we coadded 1000 individual spectra to make the plots. However, a reduction of 500 scans results in a reduction in SNR by $<10 \%$. (a) is a DLaTGS detector and (b) a MCT-B detector. The slightly higher peak SNR for the MCT-B detector is largely attributed to the enhanced sensitivity as a result of the detector cooling. However, the SNR increase is significantly less than an order of magnitude expected by comparing detector $D^{*}$. This is likely due to the elevated background signal present from the environment, as the MCT-B detector is highly sensitive to any room temperature radiation. A cold stop to remove any excess energy from the system would likely increase SNR significantly.

derived from room temperature materials, greatly affect the MCT-B detector, as many more photons from locations other than the sample are measured, increasing the detector noise, as compared to the fixed noise of the DLaTGS detector.

\section{B. Calibration Evaluation}

\section{Comparison to Existing Laboratory Measurements}

By comparing the results of a standard target in existing laboratory equipment [42] and the microscopic emission spectrometer, the level of absolute calibration can be assessed. Figure 11 is the average of 100 microemission spectra compared to the bulk measured spectrum of the quartz standard [Fig. 8(b)] of a $\sim 1 \times 1 \mathrm{~cm}$ square area. Several observations can be made when comparing these two data. First, the overall contrast between instruments is well matched, indicating that the downwelling radiance is well accounted for. Furthermore, the position and shape of the absorption features are also well matched. The only major variability in the spectrum shown occurs on the shorter wavelength side of major absorption features (e.g., $\sim 1200 \mathrm{~cm}^{-1}$, Fig. 11). This broadening of absorption features is similar to what 


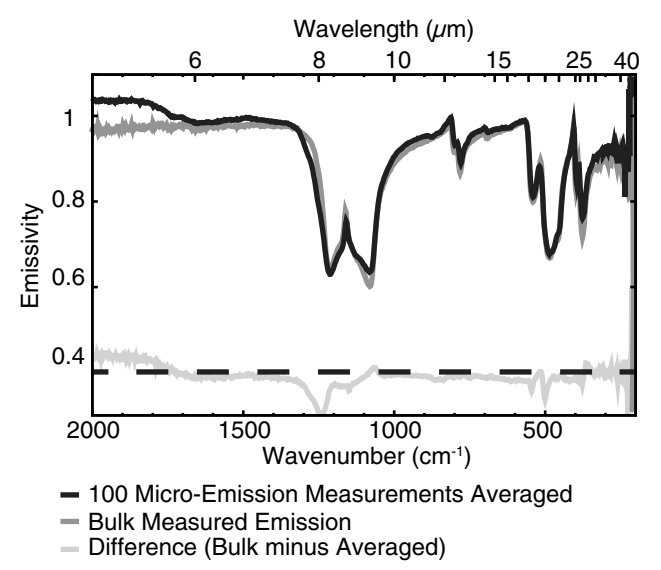

Fig. 11. Demonstration of the absolute calibration of the microemission instrument is made using a well-known sample of vein quartz. One hundred individual microemission spectra (of 500 coadds each) over a $1 \times 1 \mathrm{~cm}$ grid are averaged together and compared to a bulk measurement made with existing laboratory equipment that has been used to characterize a variety of rock forming minerals [41,42] for the analysis of martian TES data $[30,31,43,45,55,66]$. The difference between the existing laboratory and average microemission data is most pronounced as the widening of spectral features (e.g., $1250 \mathrm{~cm}^{-1}$ ). However, the depth and shape of absorption features is matched extremely well.

is observed in a bidirectional reflectance setup, such as that used by Salisbury, Walter, Vergo, and D'Aria [40] to measure the reflectance of pure geologic materials.

At very high wavenumbers ( $>1750 \mathrm{~cm}^{-1}$, Fig. 11 ), a significant divergence in the microemission and bulk measured spectra is observed. This divergence generally occurs at wavelengths shorter than the $\mathrm{Si}-\mathrm{O}$ stretching region and is introduced by an unaccounted for component in the calibration. We have determined that this emissivity excess is likely due to the anodized support structure (high emissivity) spider for the secondary mirror of the Schwarzschild being reflected onto the sample. If we include a small off-axis mirror on the back of the spider to both prevent the emitted sample energy from being reflected back onto the sample and the low emissivity of the mirror from reflecting on to the sample, this feature lessens in magnitude. Further work is under way to better characterize the effect of this calibration artifact.

\section{Crystallographic Orientation Effects}

Since the majority of emission and reflectance measurements to date are bulk measurements of many randomly oriented crystals [42], the measurement of single crystals in an unknown orientation will likely result in the observation of only one vibrational mode for the sample in question [67]. Figure 12(a) is the measurement of a quartz crystal oriented down the $c$-optical axis in the microemission spectrometer and the bulk emission spectrometer, compared to a bulk spectrum of randomly oriented quartz grains. While the microemission-oriented quartz spectrum shows many orientation effects (including missing

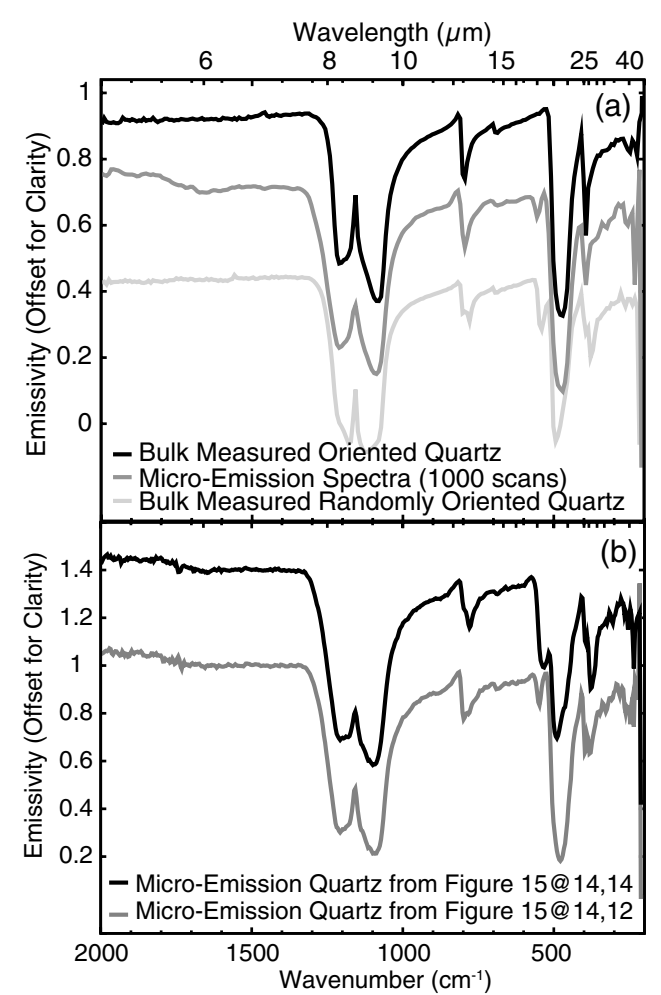

Fig. 12. (a) Bulk emission spectrum of randomly oriented quartz grains and a quartz crystal oriented down the optical $c$-axis compared to the microemission spectrum of the same oriented quartz crystal. In general, the oriented quartz crystals are lacking some of the prominent quartz doublets at $\sim 800 \mathrm{~cm}^{-1}$ and $\sim 400 \mathrm{~cm}^{-1}$. However, in the oriented quartz microscopic emission spectrum, the doublet at $\sim 550 \mathrm{~cm}^{-1}$ appears, although at a different position than in the randomly oriented quartz. This doublet does not appear in the bulk measured oriented quartz and indicates that while some crystallographic orientation effects are preserved in the microscopic emission system, the effects are not as extreme as with other optical designs. (b) Two quartz spectra extracted from the data shown in Fig. 15 illustrate the typical variability of quartz orientation effects in a natural sample. By and large, the effects are minimal and are most easily seen at the $\sim 550 \mathrm{~cm}^{-1}$ doublet.

doublets), an additional feature at $\sim 550 \mathrm{~cm}^{-1}$ is visible in the oriented microemission spectra and randomly oriented bulk measurement. This may be due to the high angle from which the photons are collected (emission angle $\sim 60^{\circ}$ ). Furthermore the emission microscope collects energy from $360^{\circ}$ simultaneously at the high emission angle, making this measurement more akin to a hemispherical or bidirectional reflectance measurement than a typical emission measurement. In an oriented quartz crystal [Fig. 12(a)], we not only view the $c$-optical axis but also observe emitted energy from the $a$-optical axis simultaneously due to the high angle. This is a significant difference from many bulk emission measurements, as they typically observe energy from $<15^{\circ}$ emission angle, enhancing the effect of optical axis orientation. Figure 12(b) shows the variability of a quartz component from a natural sample. Again the major changes occur at $\sim 550 \mathrm{~cm}^{-1}$ and do not significantly affect the identification of these 
samples as quartz. Furthermore, while some variability, similar to what is shown in Fig. 12(b), is expected for every measured spectrum, we predict that minerals with simple crystal structures (e.g., 2 optical axes) will show the strongest effect, as this instrument will not likely observe perfectly oriented crystals.

A perfectly oriented crystal is the worst-case scenario for the microemission spectrometer and any slight deviation in this perfect orientation in the crystal will result in additional optical axes being observed by the instrument and a reduction of the effect on the spectral data [Fig. 12(b)]. While this allows the spectrometer to produce data that have many similarities to bulk emission measurements, the typical simplification of the Fresnel equations $[67,68]$ to ignore orientation effects, typically represented as $\Theta$, is not possible with this setup, and the full Fresnel equations accounting for emission angle must be solved to derive the real and imaginary indices of refraction.

\section{Repeatability}

Overall when measuring a consistent and uniform sample, the microscopic emission spectrometer yields consistent results over long time periods, over various environmental conditions and instrument conditions. Furthermore, a spectrum from one sample, acquired from the same locality over the course of several days to weeks, does not change significantly in spectral shape or contrast. The variability in a mostly uniform sample, such as that shown in Figs. 8(b) and 13, which is 100 spots acquired over four days, is most likely due to small-scale variability of the sample rather than changes in downwelling radiance or instrument energy. The standard deviation of these data is very small, typically $2 \%-8 \%$ of the depth of the major absorption features, where its effect is most significant. Furthermore, the average of these 100 spots matches the bulk emission measurement of the same sample (Fig. 11), lending to the idea that the small-scale variability is included, but not separable, in the bulk measurement.

\section{Emission versus Reflectance Measurements}

When we compare the microscopic emission results to microscopic reflectance measurements (Fig. 14), in general, we find good agreement with the spectral shape and position of major absorption features. While there are significant mismatches in the Si-O stretching $\left(700-1200 \mathrm{~cm}^{-1}\right)$ and bending $\left(150-600 \mathrm{~cm}^{-1}\right)$ regions, these are not directly correlated to spectral absorption features, but rather spectral slope and the width of the features. These mismatches likely stem directly from the rudimentary calibration of the reflectance mode when compared to the calibration of the emission data. However, even with the rudimentary reflectivity calibration, the quality of the spectral data is high, making this technique a valuable addition to the instrument's wide range of capabilities. In the future,

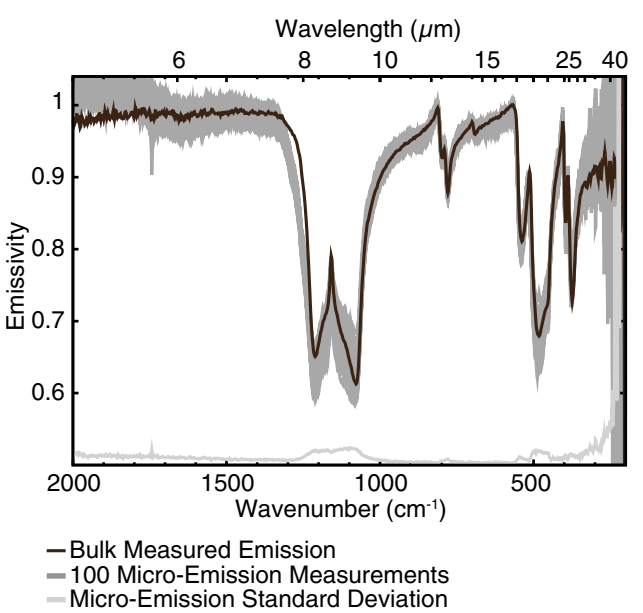

Fig. 13. (Color online) One hundred individual microemission spectra (500 coadds each) are compared to the same bulk measurement in Fig. 11. The variability in the data is likely due to small-scale $(<\overline{1 \mathrm{~mm}})$ variability in the vein quartz sample. The standard deviation of the data is also shown and is typically $\ll 5 \%$ of the lab data.

refinement of the reflectivity calibration will yield data that agree even better with the emission data. While we do not discuss this measurement style in detail, as it is primarily a demonstration of a method to acquire reflectance data, this technique could prove to be especially powerful for situations where sample heating is not permissible due to power constraints (e.g., spacecraft applications) or sample constraints (e.g., loss of volatiles at low temperatures).

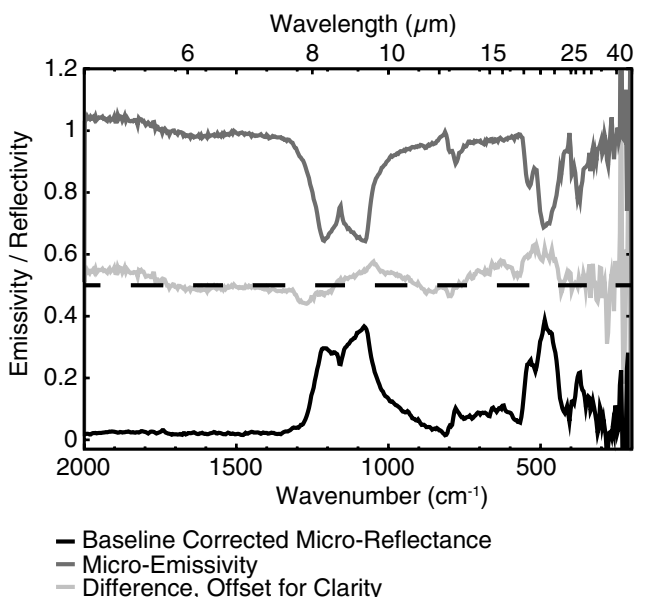

Fig. 14. Microscopic-emission and reflectance data are shown, as well as their differences. The reflectance data were calibrated using a diffuse gold reflector and have been baseline corrected to remove any spectral slope. The microscopic emission data were calibrated using the two spherical blackbody targets. In general, the spectral shapes of these two different measurements match extremely well, with all primary spectral features being well matched. While some difference exists with these two measurements, the reflectance data are considered preliminary, and with a more robust calibration routine, the majority of the difference between these data should be eliminated based on Kirchoff's Law, which states $E=1-R$ where $E$ is emissivity and $R$ is reflectivity. 


\section{Rock Sample}

The significant strength of this instrument is to performance petrographic analysis of the sample in question. This in situ, quantitative, nondestructive, mineralogical analysis of an unknown sample is a powerful tool. This technique retains geologic context [Fig. 15(a)], which is fairly unique to microscopic spectrometers. In many cases, the sample must be cored, ground into a powder, and delivered to the instrument directly, removing all geologic context. However, Fig. 15 shows a fairly typical analysis of a quartz-monzonite, where we have identified four major components throughout the sample and one accessory component [Fig. 15(b)]. Bulk emission measurements (Fig. 16) did not detect titanite due to the low areal abundance of this accessory phase in the sample (likely $<1 \%$ ). While individual microscopic emission data spots are not necessarily composed of
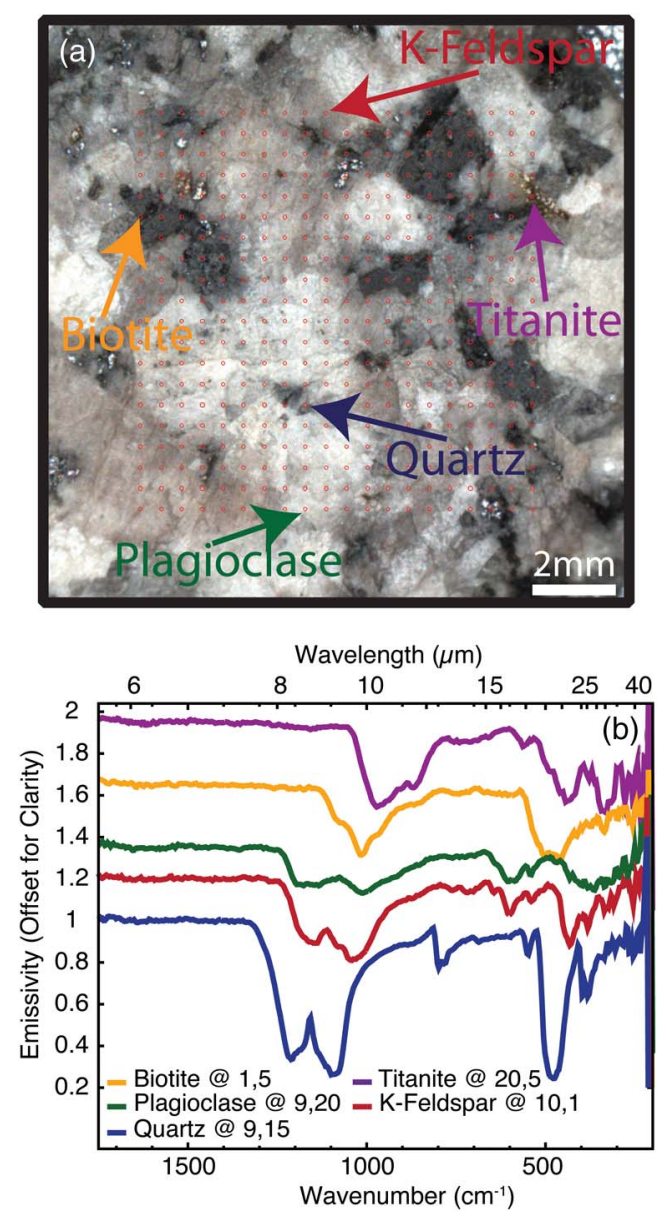

Fig. 15. (Color online) Locations (a) of microscopic-emission spectra (b) for a quartz-monzonite thick section. The red open circles are locations of individual measurements. In this sample, four major components are identified: plagioclase feldspar (white tones), potassium feldspar (pink tones), biotite (dark tones), and quartz (translucent). Quartz is not easily discernable in the visible image, as it is somewhat translucent and often appears as the color of the material surrounding or below it. A minor phase, titanite (orangegold tones), is also identified and constitutes only $\sim 3$ pixels of the 400 measured. Minor variations in individual spectra may be due to slight differences in optical axis orientation. a single component, they are general simple mixtures of only a few components, which should be identical temperatures (removing anisothermality induced slopes) and are easy to separate.

The spectral discrimination of minerals in this sample is well demonstrated (Fig. 15) and the identification of these components is straightforward. A spectral index map, decorrelation stretch [69], deconvolution $[\underline{15}, \underline{56}, \underline{70}]$ of individual points, or spectral classification are powerful tools for mapping the variability and locations of individual components in the sample. While there is some variability in the individual measurements, by and large, spectral features and shape along with the spectral contrast match the bulk emission measurement extremely well (Fig. 16) for a complicated natural geologic material. This further illustrates that the individual spectral components (e.g., 400 microemission measurements averaged together) can adequately represent the bulk emission measurement. The individual spectral components in this case include orientation effects, roughness effects, and the mineralogical variability.

However, we find the maximum variability of the individual components in this sample is generally attributed to crystallographic orientation effects [e.g., Fig. 12(b)] and mineralogical variability-not instrumentation effects or sample roughness. This allows for the quantitative identification of each component and their respective contributions to the bulk-measured spectrum to be well characterized. If we compare deconvolution results [70] of the bulk measured spectrum, using a simple endmember spectral library (Table 3), to the spectral deconvolution point counting method of the microscopic emission spectrometer described below, we find excellent agreement between the two datasets (Fig. 17).

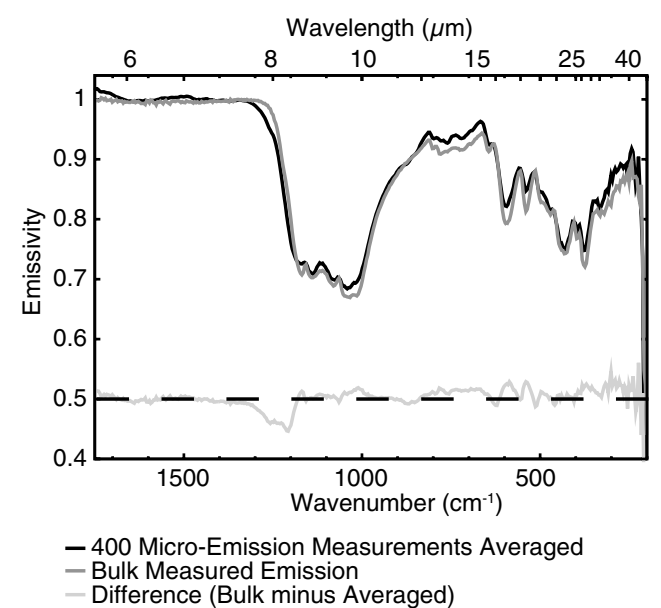

Fig. 16. Four hundred individual microemission spectra over a $1 \times 1 \mathrm{~cm}$ grid are averaged together and compared to a bulk measurement made with existing laboratory equipment. The difference between the existing laboratory and average microemission data is most pronounced as the widening of spectral features (e.g., $1225 \mathrm{~cm}^{-1}$ ). However, the depth and shape of absorption features is matched extremely well. 
Table 3. Spectral Library Used in Quantitative Mineral Abundance Determination for the Quartz-Monzonite Sample in Figs. 14-16

\begin{tabular}{llc}
\hline $\begin{array}{l}\text { Reference } \\
\text { Number/Source }\end{array}$ & \multicolumn{1}{c}{$\begin{array}{c}\text { Spectrum } \\
\text { Identifier }\end{array}$} & $\begin{array}{c}\text { Assigned } \\
\text { Mineral Group }\end{array}$ \\
\hline ASU & Quartz BUR-4120 & Quartz \\
ASU & Microcline BUR-3460 & $K$-Feldspar \\
ASU & Orthoclase WAR-RGSAN01 & $K$-Feldspar \\
ASU & Albite WAR-0235 & Plagioclase \\
ASU & Oligoclase BUR-060D & Plagioclase \\
ASU & Andesine WAR-0024 & Plagioclase \\
ASU & Labradorite BUR-3080A & Plagioclase \\
ASU & Anorthite BUR-340 & Plagioclase \\
ASU & Biotite BUR-840 & Mica \\
ASU & Chlorite WAR-1924 & Mica \\
ASU & Muscovite WAR-5474 & Mica \\
ASU & Phlogopite HS-23.3B & Mica \\
\hline
\end{tabular}

${ }^{a}$ Spectral library after Feely and Christensen [56] where, individual mineral spectra are from the ASU spectral library available online at http://speclib.asu.edu [41].

In order to perform spectral point counting, we use the same spectral library (Table 3) and unmix every individual spectrum. After the unmixing of the spectral data, we then sum all the concentrations normalized for blackbody contributions together and normalize back to $100 \%$, which results in the areal abundance of that individual spectral component. In this case, we were not interested in the variability within individual mineral groups, so all results are grouped according to Table 3 . To test the overall sensitivity of this method to components with low

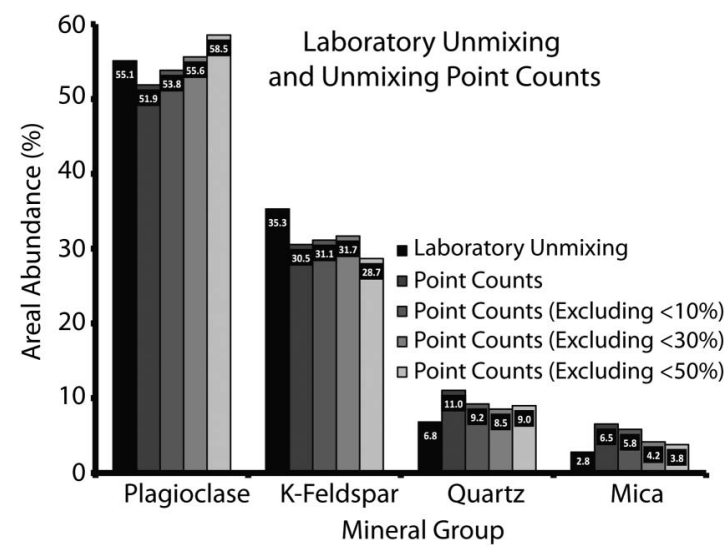

Fig. 17. Histogram of the bulk emission laboratory deconvolution mineral abundances and derived microscopic emission point count abundance. We present several methods for deriving microscopic emission point counts, where we simply deconvolve each individual spot with a simple library (Table 3 ) covering the variability in the sample, and then sum the abundances and normalize back to $100 \%$. In this case, we do not exclude minor components, as we are confident that individual pixels are generally well-modeled as they are commonly a combination of one to three endmembers. In subsequent methods, we exclude deconvolution results that have abundances less than $10 \%, 30 \%$, and $50 \%$. In each of these cases, the results do not change significantly, varying by $<5 \%$ derived mineral abundances. Furthermore the comparison to laboratory unmixing results is quite good and provides a high level of confidence in bulk spectral deconvolution and the point counting methods used to determine sample mineralogy. abundances, we exclude components with low abundances from individual spot unmixing results (Fig. 17) and then normalize the sum of all spots to $100 \%$. In general, we find that this exclusion, up to abundances $<50 \%$ does not change the derived spectral deconvolution point counting abundances more than $\sim 5 \%-6 \%$ for any given mineral group. While the absolute mineral abundances of this sample are not known, the individual determination of mineral abundances to within $\sim 5 \%$, through the disparate methods of spectral point counting and bulk spectral deconvolution, lends to the precision of emission spectroscopy for the quantitative determination of the mineralogy of natural geologic materials.

\section{Conclusions}

We have presented a brief summary of various in situ instruments that have been used to date on planetary surfaces and detailed the development of a laboratory microscopic emission and reflectance spectrometer. While in its present form the laboratory instrument is large and somewhat complicated primarily due to commercial instrument constraints, a flight prototype has been constructed where an identical microscope objective has been mounted to a flight spare mini-TES instrument, illustrating the straightforward instrument design and long heritage of TESs. Further miniaturization of this instrument is straightforward with modern electronics and the development of this instrument as a robotic armmounted device is the end goal.

We find this style of instrumentation has several obvious advantages over other in situ instrumentation proposed for planetary surface investigations, including, APXS, MB, MIs, x-ray diffraction, and $\mathrm{x}$-ray florescence spectrometers, and Raman spectrometers [71]. These advantages include a simple and tested instrument design, a long heritage of instruments sent to planetary surfaces and orbits, and the ability to make direct comparisons to existing and past instruments, as well as the ability to quantitatively determine the bulk sample mineralogy while retaining the geologic and petrologic context. Very few if any instruments mentioned above are capable of doing petrology in situ, and we find this to be a major strength of this instrument. This style of instrument could also be used for the derivation of atmospheric opacities [72] to help maintain the long record of atmospheric conditions obtained from orbiting and landed spacecraft. Furthermore, with a different microscope objective (an off-axis parabola instead of the Schwarzschild objective) that results in only a marginally larger spot size (e.g., $\sim 200-300 \mu \mathrm{m}$ ), it is possible to defocus the measurement spot to gain outcrop scale measurements comparable to existing mini-TES spatial sampling.

We thank William O'Donnell for the many hours of assistance in assembling, aligning, and optimizing this instrument spent in the laboratory. We also thank Stillman Chase, Greg Mehall, and Elliot 
Burke for detailed discussions and input on the overall instrument design and construction. Furthermore, we thank Steven Ruff, who added significant contributions to the design and calibration of this instrument and provided input on the direction of this manuscript. We also thank Michael Veto who reviewed an early draft of this manuscript. This work was funded through the NASA Planetary Geology and Geophysics research program (grant NNX08AM63G) and the Mars Instrument Development Program (grant NNX08AR07G).

\section{References}

1. R. Gellert, R. Rieder, J. Brückner, B. C. Clark, G. Dreibus, G. Klingelhöfer, G. Lugmair, D. W. Ming, H. Wänke, A. Yen, J. Zipfel, and S. W. Squyres, "Alpha particle X-ray spectrometer (APXS): results from Gusev crater and calibration report," J. Geophys. Res. 111, E02S05 (2006).

2. R. V. Morris, G. Klingelhöfer, B. Bernhardt, C. Schröder, D. S Rodionov, J. R. A. de souza, A. Yen, R. Gellert, E. N. Evlanov, J. Foh, E. Kankeleit, P. Gütlich, D. W. Ming, F. Renz, T. Wdowiak, S. W. Squyres, and R. E. Arvidson, "Mineralogy at Gusev Crater from the Mössbauer spectrometer on the Spirit Rover," Science 305, 833-836 (2004).

3. K. E. Herkenhoff, S. W. Squyres, J. F. Bell III, J. N. Maki, H. M. Arneson, P. Bertelsen, D. I. Brown, S. A. Collins, A. Dingizian, S. T. Elliott, W. Goetz, E. C. Hagerott, A. G. Hayes, M. J. Johnson, R. L. Kirk, S. McLennan, R. V. Morris, L. M. Scherr, M. A. Schwochert, L. R. Shiraishi, G. H. Smith, L. A Soderblom, J. N. Sohl-Dickstein, and M. V. Wadsworth, "Athena microscopic imager investigation," J. Geophys. Res. 108, 8065 (2003).

4. P. R. Christensen, G. L. Mehall, S. H. Silverman, S. Anwar, G. Cannon, N. Gorelick, R. Keehn, T. Tourville, D. Bates, S. Ferry, T. Fortuna, J. Jeffryes, W. O'Donnell, R. Peralta, T. Wolverton, D. Blaney, R. Denise, J. Rademacher, R. V. Morris, and S. Squyres, "The miniature thermal emission spectrometer for the Mars Exploration Rovers," J. Geophys. Res. 108, 8064 (2003).

5. J. F. Bell III, J. Joseph, J. N. Sohl-Dickstein, H. M. Arneson, M. J. Johnson, M. T. Lemmon, and D. Savransky, "In-flight calibration and performance of the Mars Exploration Rover Panoramic Camera (Pancam) instruments," J. Geophys. Res. 111, E02S03 (2006).

6. S. W. Squyres, R. E. Arvidson, S. Ruff, R. Gellert, R. V. Morris, D. W. Ming, L. Crumpler, J. D. Farmer, D. J. Des Marais, A. Yen, S. M. McLennan, W. Calvin, J. F. Bell III, B. C. Clark, A. Wang, T. J. McCoy, M. E. Schmidt, and P. A. de Souza, Jr, "Detection of silica-rich deposits on Mars," Science 320, 1063-1067 (2008).

7. R. Gellert, R. Rieder, R. C. Anderson, J. Brückner, B. C. Clark, G. Greibus, T. Economou, G. Klingelhöfer, G. W. Lugmain, D. W. Ming, S. W. Squyres, C. d'Uston, H. Wänke, A. Yen, and J. Zipfel, "Chemistry of rocks and soils at Gusev Crater from the alpha particle X-ray spectrometer," Science $\mathbf{3 0 5}$, 829-832 (2004).

8. M. P. Golombek, J. A. Grant, L. S. Crumpler, R. Greeley, R. E. Arvidson, I. J. F. Bell III, C. M. Weitz, R. Sullivan, P. R. Christensen, L. A. Soderblom, and S. W. Squyres, "Erosion rates at the Mars Exploration Rover landing sites and long-term climate change on Mars," J. Geophys. Res. 111, E12S10 (2006).

9. S. M. McLennan, J. F. Bell III, W. M. Calvin, P. R. Christensen, B. C. Clark, P. A. de Souza, J. Farmer, W. H. Farrand, D. A. Fike, R. Gellert, A. Ghosh, T. D. Glotch, J. P. Grotzinger, B. Hahn, K. E. Herkenhoff, J. A. Hurowitz, J. R. Johnson, S. S. Johnson, B. Jolliff, G. Klingelhöfer, A. H. Knoll, Z. Learner, M. C. Malin, H. Y. McSween, Jr., J. Pocock, S. W. Ruff, L. A. Soderblom, S. W. Squyres, N. J. Tosca, W. A. Watters, M. B. Wyatt, and A. Yen, "Provenance and diagenesis of the evaporite-bearing burns formation, Meridiani Planum, Mars," Earth Planet. Sci. Lett. 240, 95-121 (2005).
10. S. W. Ruff, P. R. Christensen, D. L. Blaney, W. H. Farrand, J. R Johnson, J. R. Michalski, J. E. Moersch, S. P. Wright, and S. W. Squyres, "The rocks of Gusev Crater as viewed by the MiniTES instrument," J. Geophys. Res. 111, E12S18 (2006).

11. S. W. Ruff, J. D. Farmer, W. M. Calvin, K. E. Herkenhoff, J. R. Johnson, R. V. Morris, M. S. Rice, R. E. Arvidson, J. F. Bell III, P. R. Christensen, and S. W. Squyres, "Characteristics, distribution, origin, and significance of opaline silica observed by the Spirit Rover in Gusev Crater, Mars," J. Geophys. Res. 116, E00F23 (2011).

12. S. W. Squyres, O. Aharonson, B. C. Clark, B. A. Cohen, L. Crumpler, P. A. de Souza, W. H. Farrand, R. Gellert, J. Grant, J. P. Grotzinger, A. F. C. Haldemann, J. R. Johnson, G. Klingelhofer, K. W. Lewis, R. Li, T. McCoy, A. S. McEwen, H. Y. McSween, D. W. Ming, J. M. Moore, R. V. Morris, T. J. Parker, J. W. Rice, Jr., S. Ruff, M. Schmidt, C. Schroder, L. A. Soderblom, and A. Yen, "Pyroclastic activity at home plate in Gusev Crater, Mars," Science 316, 738-742 (2007).

13. K. W. Lewis, O. Aharonson, J. P. Grotzinger, S. W. Squyres, J. F. Bell III, L. S. Crumpler, and M. E. Schmidt, "Structure and stratigraphy of home plate from the Spirit Mars Exploration Rover," J. Geophys. Res. 113, E12S36 (2008).

14. G. Klingelhöfer, R. V. Morris, B. Bernhardt, C. Schröder, D. S. Rodionov, J. R. A. de souza, A. Yen, R. Gellert, E. N. Evlanov, B. Zubkov, J. Foh, E. Kankeleit, P. Gütlich, D. W. Ming, F. Renz, T. Wdowiak, S. W. Squyres, and R. E. Arvidson, "Jarosite and hematite at Meridiani Planum from the Mössbauer spectrometer on the opportunity rover," Science 306, 1740-1745 (2004).

15. A. D. Rogers and O. Aharonson, "Mineralogical composition of sands in Meridiani Planum determined from Mars Exploration Rover data and comparison to orbital measurements," J. Geophys. Res. 113, E06S14 (2008).

16. J. P. Grotzinger, J. Crisp, A. R. Vasavada, R. C. Anderson, C. J. Baker, R. Barry, D. F. Blake, P. Conrad, K. S. Edgett, B. Ferdowski, R. Gellert, J. B. Gilbert, M. Golombek, J. Gomez-Elvira, D. M. Hassler, L. Jandura, M. Litvak, P. Mahaffy, J. Maki, M. Meyer, M. C. Malin, I. Mitrofanov, J. J. Simmonds, D. Vaniman, R. V. Welch, and R. C. Wiens, "Mars Science Laboratory mission and science investigation," Space Sci. Rev. 170(2), 5-56 (2012).

17. S. Maurice, R. C. Wiens, M. Saccoccio, B. Barraclough, O. Gasnault, O. Forni, N. Mangold, D. Baratoux, S. Bender, G. Berger, J. Bernardin, M. Berthe, N. Bridges, D. Blaney, M. Bouye, P. Cais, B. Clark, S. Clegg, A. Cousin, D. Cremers, A. Cros, L. DeFlores, C. Derycke, B. Dingler, G. Dromart, B. Dubois, M. Dupieux, E. Durand, L. d'Uston, C. Fabre, B. Faure, A. Gaboriaud, T. Gharsa, K. Herkenhoff, E. Kan, L. Kirkland, D. Kouach, J. L. Lacour, Y. Langevin, J. Lasue, S. Le Mouelic, M. Lescure, E. Lewin, D. Limonadi, G. Manhes, P. Mauchien, C. McKay, P. Y. Meslin, Y. Michel, E. Miller, H. E. Newsom, G. Orttner, A. Paillet, L. Pares, Y. Parot, R. Perez, P. Pinet, F. Poitrasson, B. Quertier, B. Salle, C. Sotin, V. Sautter, H. Seran, J. J. Simmonds, J. B. Sirven, R. Stiglich, N. Striebig, J. J. Thocaven, M. J. Toplis, and D. Vaniman, "The ChemCam instrument suite on the Mars Science Laboratory (MSL) Rover: science objectives and mast unit description," Space Sci. Rev. 170(2), 95-166 (2012).

18. R. C. Wiens, S. Maurice, B. Barraclough, M. Saccoccio, W. C. Barkley, J. F. Bell III, S. Bender, J. Bernardin, D. Blaney, J. Blank, M. Bouye, N. Bridges, N. Bultman, P. Cais, R. C. Clanton, B. Clark, S. Clegg, A. Cousin, D. Cremers, A. Cros, L. DeFlores, D. Delapp, R. Dingler, C. D'Uston, M. D. Dyar, T. Elliott, D. Enemark, C. Fabre, M. Flores, O. Forni, O. Gasnault, T. Hale, C. Hays, K. Herkenhoff, E. Kan, L. Kirkland, D. Kouach, D. Landis, Y. Langevin, N. Lanza, F. LaRocca, J. Lasue, J. Latino, D. Limonadi, C. Lindensmith, C. Little, N. Mangold, G. Manhes, P. Mauchien, C. McKay, E. Miller, J. Mooney, R. V. Morris, L. Morrison, T. Nelson, H. Newsom, A. Ollila, M. Ott, L. Pares, R. Perez, F. Poitrasson, C. Provost, J. W. Reiter, T. Roberts, F. Romero, V. Sautter, S. Salazar, J. J. Simmonds, R. Stiglich, S. Storms, N. Striebig, J. J. Thocaven, T. Trujillo, M. Ulibarri, D. Vaniman, N. Warner, R. Waterbury, R. Whitaker, J. Witt, and B. Wong-Swanson, "The ChemCam instrument suite on the Mars Science 
Laboratory (MSL) rover: body unit and combined system tests," Space Sci. Rev. 170(4), 167-227 (2012).

19. K. Edgett, R. A. Yingst, M. Ravine, M. Caplinger, J. Maki, F. T. Ghaemi, J. Schaffner, J. Bell III, L. Edwards, K. Herkenhoff, E. Heydari, L. Kah, M. Lemmon, M. Minitti, T. Olson, T. Parker, S. Rowland, J. Schieber, R. Sullivan, D. Sumner, P. Thomas, E. Jensen, J. Simmonds, A. Sengstacken, R. Willson, and W. Goetz, "Curiosity's Mars Hand Lens Imager (MAHLI) investigation," Space Sci. Rev. 170(4), 259-317 (2012).

20. D. Blake, D. Vaniman, C. Achilles, R. Anderson, D. Bish, T. Bristow, C. Chen, S. Chipera, J. Crisp, D. Des Marais, R. Downs, J. Farmer, S. Feldman, M. Fonda, M. Gailhanou, H. Ma, D. Ming, R. Morris, P. Sarrazin, E. Stolper, A. Treiman, and A. Yen, "Characterization and calibration of the CheMin mineralogical instrument on Mars Science Laboratory," Space Sci. Rev. 170(1), 341-399 (2012).

21. P. Mahaffy, C. Webster, M. Cabane, P. Conrad, P. Coll, S. Atreya, R. Arvey, M. Barciniak, M. Benna, L. Bleacher, W. Brinckerhoff, J. Eigenbrode, D. Carignan, M. Cascia, R. Chalmers, J. Dworkin, T. Errigo, P. Everson, H. Franz, R. Farley, S. Feng, G. Frazier, C. Freissinet, D. Glavin, D. Harpold, D. Hawk, V. Holmes, C. Johnson, A. Jones, P. Jordan, J. Kellogg, J. Lewis, E. Lyness, C. Malespin, D. Martin, J. Maurer, A. McAdam, D. McLennan, T. Nolan, M. Noriega, A. Pavlov, B. Prats, E. Raaen, O. Sheinman, D. Sheppard, J. Smith, J. Stern, F. Tan, M. Trainer, D. Ming, R. Morris, J. Jones, C. Gundersen, A. Steele, J. Wray, O. Botta, L. Leshin, T. Owen, S. Battel, B. Jakosky, H. Manning, S. Squyres, R. Navarro-González, C. McKay, F. Raulin, R. Sternberg, A. Buch, P. Sorensen, R. Kline-Schoder, D. Coscia, C. Szopa, S. Teinturier, C. Baffes, J. Feldman, G. Flesch, S. Forouhar, R Garcia, D. Keymeulen, S. Woodward, B. Block, K. Arnett, R. Miller, C. Edmonson, S. Gorevan, and E. Mumm, "The sample analysis at Mars investigation and instrument suite," Space Sci. Rev. 170(4), 401-478 (2012).

22. P. R. Christensen, D. L. Anderson, S. C. Chase, R. T. Clancy, R. N. Clark, B. J. Conrath, H. H. Kieffer, R. O. Kuzmin, M. C. Malin, J. C. Pearl, T. L. Roush, and M. D. Smith, "Results from the Mars global surveyor thermal emission spectrometer investigation," Science 279, 1692-1698 (1998).

23. P. R. Christensen, B. M. Jakosky, H. H. Kieffer, M. C. Malin, H. Y. McSween, Jr., K. Nealson, G. L. Mehall, S. H. Silverman, S. Ferry, M. Caplinger, and M. Ravine, "The thermal emission imaging system (THEMIS) for the Mars 2001 odyssey mission," Space Sci. Rev. 110(1-2), 85-130 (2004).

24. S. Murchie, R. Arvidson, P. Bedini, K. Beisser, J. P. Bibring, J. Bishop, J. Boldt, P. Cavender, T. Choo, and R. T. Clancy, "Compact reconnaissance imaging spectrometer for Mars (CRISM) on Mars reconnaissance orbiter (MRO)," J. Geophys. Res. 112, E05S03 (2007).

25. J.-P. Bibring, Y. Langevin, A. Gendrin, B. Gondet, F. Poulet, M. Berthé, A. Soufflot, R. Arvidson, N. Mangold, J. Mustard, and P. Drossart, and Omega-Team, "Mars surface diversity as revealed by the OMEGA/Mars express observations," Science 307, 1576-1581 (2005).

26. E. B. Wilson, Jr., J. C. Decius, and P. C. Cross, Molecular Vibrations: The Theory of Infrared and Raman Vibrational Spectra (McGraw-Hill, 1955).

27. V. C. Farmer, The Infrared Spectra of Minerals (Mineralogical Society, 1974).

28. V. E. Hamilton and P. R. Christensen, "Determining the modal mineralogy of mafic and ultramafic igneous rocks using thermal emission spectroscopy," J. Geophys. Res. 105, 9717-9734 (2000).

29. T. D. Glotch, R. V. Morris, P. R. Christensen, and T. G. Sharp, "Effect of precursor mineralogy on the thermal infrared emission spectra of hematite: application to martian hematite mineralization," J. Geophys. Res. 109, E07003 (2004).

30. S. W. Ruff, "Spectral evidence for zeolite in the dust on Mars," Icarus 168, 131-143 (2004).

31. J. L. Bandfield, V. E. Hamilton, and P. R. Christensen, "A global view of Martian volcanic compositions," Science 287, 1626-1630 (2000).
32. J. F. Mustard and J. E. Hays, "Effects of hyperfine particles on reflectance spectra from 0.3 to $25 \mu \mathrm{m}$," Icarus 125, 145-163 (1997).

33. G. R. Hunt and J. W. Salisbury, "Mid-infrared spectral behavior of metamorphic rocks," Environ. Res. Paper 543-AFCRLTR-76-0003, 67 (1976).

34. Y. Yamaguchi, A. B. Kahle, H. Tsu, T. Kawakami, and M. Pniel, "Overview of advanced spaceborne thermal emission and reflection radiometer (ASTER)," IEEE Trans. Geosci. Remote Sens. 36, 1062-1071 (1998).

35. P. R. Christensen, J. L. Bandfield, J. F. Bell III, N. Gorelick, V. E. Hamilton, A. Ivanov, B. M. Jakosky, H. H. Kieffer, M. D. Lane, M. C. Malin, G. L. Mehall, T. McConnochie, A. S. McEwen, H. Y. McSween, Jr., J. E. Moersch, K. H. Nealson, J. W. Rice, Jr., M. I. Richardson, S. W. Ruff, M. D. Smith, T. N. Titus, and W. Wyatt, "Morphology and composition of the surface of Mars: Mars Odyssey THEMIS results," Science 300, 2056-2061 (2003).

36. P. R. Christensen, H. Y. McSween, Jr., J. L. Bandfield, S. W. Ruff, A. D. Rogers, V. E. Hamilton, N. Gorelick, M. B. Wyatt, B. M. Jakosky, H. H. Kieffer, M. C. Malin, and J. E. Moersch, "Evidence for igneous diversity and magmatic evolution on Mars from infrared spectral observations," Nature 436, 882 (2005).

37. A. D. Rogers, P. R. Christensen, and J. L. Bandfield, "Compositional heterogeneity of the ancient martian crust: analysis of Ares Vallis bedrock the THEMIS and TES data," J. Geophys. Res. 110, E05010 (2005).

38. T. D. Glotch and P. R. Christensen, "Geologic and mineralogic mapping of Aram Chaos: evidence for a water-rich history," J. Geophys. Res. 110, E09006 (2005).

39. M. S. Ramsey and P. R. Christensen, "Mineral abundance determination: quantitative deconvolution of thermal emission spectra," J. Geophys. Res. 103, 577-596 (1998).

40. J. W. Salisbury, L. S. Walter, N. Vergo, and D. M. D'Aria, Infrared (2.1-25 $\mu \mathrm{m})$ Spectra of Minerals (Johns Hopkins University, 1992).

41. P. R. Christensen, J. L. Bandfield, V. E. Hamilton, D. A. Howard, M. D. Lane, J. L. Piatek, S. W. Ruff, and W. L. Stefanov, "A thermal emission spectral library of rock forming minerals,” J. Geophys. Res. 105, 9735-9739 (2000).

42. S. W. Ruff, P. R. Christensen, P. W. Barbera, and D. L. Anderson, "Quantitative thermal emission spectroscopy of minerals: a technique for measurement and calibration," J. Geophys. Res. 102, 14899-14913 (1997).

43. V. E. Hamilton and P. R. Christensen, "Evidence for extensive olivine-rich bedrock in Nili Fossae, Mars," Geology 33, 433-436 (2005).

44. J. L. Bandfield, A. D. Rogers, and C. S. Edwards, "The role of aqueous alteration in the formation of martian soils," Icarus 211, 157-171 (2011).

45. W. C. Koeppen and V. E. Hamilton, "Global distribution, composition, and abundance of olivine on the surface of Mars from thermal infrared data," J. Geophys. Res. 113, E05001 (2008).

46. M. D. Lane, T. D. Glotch, M. D. Dyar, C. M. Pieters, R. Klima, T. Hiroi, J. L. Bishop, and J. Sunshine, "Midinfrared spectroscopy of synthetic olivines: thermal emission, specular and diffuse reflectance, and attenuated total reflectance studies of forsterite to fayalite," J. Geophys. Res. 116, E08010 (2011).

47. J. W. Salisbury and J. W. Eastes, "The effect of particle size and porosity on spectral contrast in the mid-infrared," Icarus 64, 586-588 (1985).

48. J. E. Moersch and P. R. Christensen, "Thermal emission from particulate surfaces: a comparison of scattering models with measured spectra," J. Geophys. Res. 100, 7465-7477 (1995).

49. V. E. Hamilton, P. R. Christensen, H. Y. McSween, Jr., and J. L. Bandfield, "Searching for the source regions of martian meteorites using MGS TES: integrating martian meteorites into the global distribution of igneous materials on Mars," Meteorit. Planet. Sci. 38, 871-885 (2003).

50. M. A. Presley and P. R. Christensen, "Thermal conductivity measurements of particulate materials, part I: a review," J. Geophys. Res. 102, 6535-6549 (1997). 
51. S. W. Ruff and P. R. Christensen, "Basaltic andesite, altered basalt, and a TES-based search for smectite clay minerals on Mars," Geophys. Res. Lett. 34, L10204 (2007).

52. J. M. Bennett and E. Ashley, "Infrared reflectance and emittance of silver and gold evaporated in ultrahigh vacuum," Appl. Opt. 4, 221-224 (1965).

53. T. D. Glotch, P. R. Christensen, and T. G. Sharp, "Fresnel modeling of hematite crystal surfaces and application to martian hematite spherules," Icarus 181, 408-418 (2006).

54. A. D. Rogers and P. R. Christensen, "Surface mineralogy of martian low-albedo regions from MGS TES data: implications for crustal evolution and surface alteration," J. Geophys. Res. 112, E01003 (2007).

55. C. S. Edwards, P. R. Christensen, and V. E. Hamilton, "Evidence for extensive olivine-rich basalt bedrock outcrops in Ganges and Eos chasmas, Mars," J. Geophys. Res. 113, E11003 (2008).

56. K. C. Feely and P. R. Christensen, "Quantitative compositional analysis using thermal emission spectroscopy: application to igneous and metamorphic rocks," J. Geophys. Res. 104, 24195-24210 (1999).

57. A. R. Vasavada, J. L. Bandfield, B. T. Greenhagen, P. O. Hayne, M. A. Siegler, J.-P. Williams, and D. A. Paige, "Lunar equatorial surface temperatures and regolith properties from the Diviner Lunar Radiometer experiment," J. Geophys. Res. 117, E00H18 (2012).

58. D. L. Stierwalt, J. B. Bernstein, and D. D. Kirk, "Measurement of the infrared spectral absorptance of optical materials," Appl. Opt. 2, 1169-1173 (1963).

59. D. Kember, D. H. Chenery, N. Sheppard, and J. Fell, "Fouriertransform i.r. emission studies of weakly emitting overlayers on metal surfaces; experimental and spectral-ratioing procedures and the comparative use of room temperature triglycine sulphate and low-temperature mercury cadmium telluride detectors," Spectrochim. Acta Part A 35, 455-459 (1979).

60. F. J. DeBlase and S. Compton, "Infrared emission spectroscopy: a theoretical and experimental review," Appl. Spectrosc. 45, 611-618 (1991).

61. R. T. Rewick and R. G. Messerschmidt, "A simple device for studying FT-IR emission spectra of solid surfaces," Appl. Spectrosc. 45, 297-301 (1991).

62. P. R. Christensen and S. T. Harrison, "Thermal infrared emission spectroscopy of natural surfaces: application to desert varnish coatings on rocks," J. Geophys. Res. 98, 19819-19834 (1993).
63. R. A. Hanel, B. J. Conrath, V. G. Kunde, C. Prabhakara, I. Revah, V. V. Salomonson, and G. Wolford, "The Nimbus 4 infrared spectroscopy experiment 1 . Calibrated thermal emission spectra," J. Geophys. Res. 77, 2629-2641 (1972).

64. R. J. P. Lyon, "Evaluation of infrared spectroscopy for compositional analysis of lunar and planetary soils," in Stanford Research Institute Final Report Contract NASr (Stanford Research Institute, 1962).

65. R. L. Henry, "The transmission of powder films in the infrared," J. Opt. Soc. Am. 38, 775-787 (1948).

66. P. R. Christensen, J. L. Bandfield, V. E. Hamilton, S. W. Ruff, H. H. Kieffer, T. Titus, M. C. Malin, R. V. Morris, M. D. Lane, R. N. Clark, B. M. Jakosky, M. T. Mellon, J. C. Pearl, B. J. Conrath, M. D. Smith, R. T. Clancy, R. O. Kuzmin, T. Roush, G. L. Mehall, N. Gorelick, K. Bender, K. Murray, S. Dason, E. Greene, S. H. Silverman, and M. Greenfield, "Mars Global Surveyor Thermal Emission Spectrometer experiment: description and surface science results," J. Geophys. Res. 106, 23823-23871 (2001).

67. M. D. Lane, "Infrared optical constants of calcite and their relationship to particle size effects in thermal emission spectra of granular calcite," J. Geophys. Res. 104, 14099-14108 (1999).

68. J. B. Pollack, T. Roush, F. Witteborn, J. Bregman, D. Wooden, C. Stoker, O. B. Toon, D. Rank, B. Dalton, and R. Freedman, "Thermal emission spectra of Mars (5.4-10.5 $\mu \mathrm{m})$ : evidence for sulfates, carbonates, and hydrates," J. Geophys. Res. 95, 14595-14627 (1990)

69. A. R. Gillespie, A. B. Kahle, and R. E. Walker, "Color enhancement of highly correlated images. I. Decorrelation and HSI contrast stretches," Remote Sens. Environ. 20, 209-235 (1986).

70. M. S. Ramsey, P. R. Christensen, N. Lancaster, and D. A. Howard, "Identification of sand sources and transport pathways at Kelso Dunes, California using thermal infrared remote sensing," Geol. Soc. Am. Bull. 111, 646-662 (1999).

71. J. Blacksberg, G. R. Rossman, and A. Gleckler, "Time-resolved Raman spectroscopy for in situ planetary mineralogy," Appl. Opt. 49, 4951-4962 (2010).

72. M. D. Smith, M. J. Wolff, M. T. Lemmon, N. Spanovich, D. Banfield, C. J. Budney, R. T. Clancy, A. Ghosh, G. A. Landis, P. Smith, B. Whitney, P. R. Christensen, and S. W. Squyres, "First atmospheric results from the Mars Exploration rovers Mini-TES," Science 306, 1750-1753 (2004). 